\title{
Determination and analysis of in situ spectral aerosol optical properties by a multi-instrumental approach
}

\author{
S. Segura ${ }^{1}$, V. Estellés ${ }^{1}$, G. Titos ${ }^{2}$, H. Lyamani' ${ }^{2}$, M. P. Utrillas ${ }^{1}$, P. Zotter ${ }^{3}$, A. S. H. Prévôt ${ }^{3}$, G. Močnik ${ }^{4}$, \\ L. Alados-Arboledas ${ }^{2}$, and J. A. Martínez-Lozano ${ }^{1}$ \\ ${ }^{1}$ Departament de Física de la Terra i Termodinàmica, Universitat de València, Burjassot (Valencia), Spain \\ ${ }^{2}$ Andalusian Institute for Earth System Research, IISTA-CEAMA, University of Granada, Junta de Andalucía, \\ Granada, 18006, Spain \\ ${ }^{3}$ Laboratory Atmospheric Chemistry (LAC), Paul Scherrer Institute, Villigen, Switzerland \\ ${ }^{4}$ Aerosol d. o. o., Research and Development Department, Ljubljana, Slovenia \\ Correspondence to: S. Segura (sara.segura@uv.es)
}

Received: 19 December 2013 - Published in Atmos. Meas. Tech. Discuss.: 26 February 2014

Revised: 21 May 2014 - Accepted: 27 June 2014 - Published: 6 August 2014

\begin{abstract}
Continuous in situ measurements of aerosol optical properties were conducted from 29 June to 29 July 2012 in Granada (Spain) with a seven-wavelength Aethalometer, a Multi-Angle Absorption Photometer, and a three-wavelength integrating nephelometer. The aim of this work is to describe a methodology to obtain the absorption coefficients $\left(b_{\mathrm{abs}}\right)$ for the different Aethalometer wavelengths. In this way, data have been compensated using algorithms which best estimate the compensation factors needed. Two empirical factors are used to infer the absorption coefficients from the Aethalometer measurements: $C$ - the parameter describing the enhancement of absorption by particles in the filter matrix due to multiple scattering of light in the filter matrix - and $f$, the parameter compensating for non-linear loading effects in the filter matrix. Spectral dependence of $f$ found in this study is not very strong. Values for the campaign lie in the range from 1.15 at $370 \mathrm{~nm}$ to 1.11 at $950 \mathrm{~nm}$. Wavelength dependence in $C$ proves to be more important, and also more difficult to calculate. The values obtained span from 3.42 at $370 \mathrm{~nm}$ to 4.59 at $950 \mathrm{~nm}$. Furthermore, the temporal evolution of the Ångström exponent of absorption $\left(\alpha_{\mathrm{abs}}\right)$ and the singlescattering albedo $\left(\omega_{0}\right)$ is presented. On average $\alpha_{\mathrm{abs}}$ is around $1.1 \pm 0.3$, and $\omega_{0}$ is $0.78 \pm 0.08$ and $0.74 \pm 0.09$ at 370 and $950 \mathrm{~nm}$, respectively. These are typical values for sites with a predominance of absorbing particles, and the urban measurement site in this study is such. The $b_{\mathrm{abs}}$ average values are of $16 \pm 10 \mathrm{Mm}^{-1}$ (at $370 \mathrm{~nm}$ ) and $5 \pm 3 \mathrm{Mm}^{-1}$ (at $950 \mathrm{~nm}$ ), respectively. Finally, differences between workdays and Sun-
\end{abstract}

days have been further analysed, obtaining higher $b_{\text {abs }}$ and lower $\omega_{0}$ during the workdays than on Sundays as a consequence of the diesel traffic influence.

\section{Introduction}

The radiative forcing in the Earth's atmosphere caused by aerosols is highly uncertain (IPCC, 2013). The direct effect of aerosol influence is exhibited by scattering and/or absorbing solar radiation. By scattering the light they contribute to the cooling of the underlying atmosphere and the surface (negative radiative forcing). Furthermore, by absorbing light they contribute to the heating of the atmosphere (positive radiative forcing). The latter is an important component of the radiation budget of the atmosphere which still needs to be better characterized to reduce uncertainties in climate models (Houghton et al., 2001; Ramanathan et al., 2001; Kirchstetter et al., 2004).

The major light-absorbing compounds among aerosols are carbonaceous substances and mineral dust. However, the spectral dependence of the aerosol absorption coefficient varies depending on their chemical and physical properties. Light absorption by black carbon (BC) is generally considered to vary weakly with wavelength (Bergstrom et al., 2007). Nevertheless, other aerosol components - such as desert aerosols (Dubovik et al., 2002), organic compounds (Jacobson, 1998), or biomass burning (Mukai and Ambe, 
1986) - exhibit a stronger wavelength dependence. Therefore, the spectral dependence of aerosol absorption coefficient is important to distinguish different aerosol-absorbing components (Collaud-Coen et. al, 2004; Fialho et al., 2005; Sandradewi et al., 2008a).

Different methods and instruments are used to measure light absorption (Hansen et al., 1984; Horvath, 1993; Bond and Bergstrom, 2006; Moosmüller et al., 2009; Müller et al., 2011). The most widely used method for in situ measurements is the filter-based technique, which relies on determining the absorption coefficient by measuring the change of light attenuation due by aerosol collected on a filter matrix (Hansen et al., 1982). Instruments currently used for determining the aerosol absorption coefficient using filter-based techniques are the Aethalometer (Hansen et al., 1984), the Particle Soot Absorption Photometer (PSAP) (Bond et al., 1999) and the Multi-Angle Absorption Photometer (MAAP) (Petzold and Schönlinner, 2004).

It is known that all filter-based instruments suffer from several artefacts (Schmid et al., 2006; Müller et al., 2011; Collaud-Coen et al., 2010). Therefore, it is necessary to apply compensation to the data to determine the absorption coefficient. Several studies have proposed different numerical methods to compensate these artefacts (Bond et al., 1999; Weingartner et al., 2003; Arnott et al., 2005; Schmid et al., 2006), and have proven to give quite satisfactory results when compared to other non-filter-based instruments.

From the instruments mentioned above, the MAAP is one of the newer filter-based instrument for measuring the aerosol absorption coefficient (Petzold and Schönlinner, 2004; Petzold et al., 2005). Measurements provided by the MAAP are only available for one wavelength, which is a disadvantage since it is important to determine both $b_{\text {abs }}$ and its spectral dependence. This information can be obtained by combining the MAAP measurements with those performed by a multi-wavelength Aethalometer AE-31, which performs measurements at seven different channels covering the range from the ultraviolet (UV, $370 \mathrm{~nm}$ ) to near infrared (NIR, $950 \mathrm{~nm})$.

The aim of this work is to obtain the spectral variation of the compensation factors of the Aethalometer data and then apply them to the measurements performed at the different channels of the Aethalometer. In this way, the aerosol absorption coefficients at all the different Aethalometer channels are calculated, and then other optical parameters, such as the spectral single-scattering albedo $\left(\omega_{0}\right)$ or the Ångström exponent of absorption $\left(\alpha_{\mathrm{abs}}\right)$, are determined and analysed.

The data set presented in this study was measured during one month, from 29 June 2012 to 29 July 2012, in Granada (Spain) using a MAAP, an Aethalometer, and a nephelometer. In this work we will discuss the methodology used for compensating the Aethalometer and MAAP data. Finally, the temporal evolution of the results obtained is presented and compared with results in other works to evaluate the reliability of the data.

\section{Site description and instrumentation}

\subsection{Measurement site}

Measurements presented in this study were performed in Granada, from 29 June to 29 July 2012. Granada $\left(37.18^{\circ} \mathrm{N}, 3.58^{\circ} \mathrm{W}, 680 \mathrm{~m}\right.$ a.s.l.) is a non-industrialized medium-size city located in southeastern Spain with a population of around 500000 inhabitants, considering the whole metropolitan area (http://www.juntadeandalucia.es/). Nearcontinental conditions prevail at this site and are responsible for large temperature differences, providing cool winters and hot summers (Lyamani et al., 2010).

The measurement station is located in the southern part of the city, less than $500 \mathrm{~m}$ away from a highway that surrounds the city. Local aerosol sources are mainly road traffic (dominated by diesel engines) together with soil re-suspension, especially during the warm-dry season when the reduced rainfall may increase the contribution of local mineral dust. Due to its location in the Mediterranean basin, it is influenced by two major aerosol source regions: Europe, as a source of anthropogenic pollutants, and northern Africa, as a source of natural mineral dust (Lyamani et al., 2010).

\subsection{Instrumentation}

Sampling for all the different instruments was obtained using a stainless steel tube $20 \mathrm{~cm}$ in diameter $5 \mathrm{~m}$ in length (Lyamany et al., 2008). The inlet was located about $15 \mathrm{~m}$ above the ground. Measurements were carried out without an aerosol size cut-off or heating of the sampled air. From the tube, several stainless steel pipes led the sampled air to each instrument at the appropriate flows. Different diameters were adjusted to maintain the laminar flow in the tubes and minimize particle losses (Baron and Willeke, 2005).

The aerosol light absorption coefficient was measured using two different filter-based instruments. The MAAP (Thermo Scientific) measures the light transmitted through and backscattered from a particle-loaded filter. The $b_{\text {abs }}$ at $637 \mathrm{~nm}$ (Müller et al., 2011) is calculated using radiative transfer model which includes a treatment of the scattering effects of the filter matrix and the light scattered by the aerosol component. A detailed description of the method is provided by Petzold and Schönlinner (2004). The MAAP works at a constant flow rate of $16.7 \mathrm{~L} \mathrm{~min}^{-1}$ and provides measurements every minute. The total method uncertainty for the aerosol light absorption coefficient inferred from MAAP measurement is around $12 \%$ (Petzold and Schönlinner, 2004; Petzold et al., 2005).

The MAAP was believed to be the instrument which is the least affected by artefacts for obtaining the aerosol absorption coefficient among all the different filter-based methods. Different studies have shown that $b_{\text {abs }}$ measured by MAAP is in good agreement with those measured by photoacoustic spectrometry (e.g. Petzold et al., 2005; Sheridan et al., 2005). 
However, a recent study by Hyvärinen et al. (2013) showed that MAAP measurements suffer from some artefacts in locations with high concentrations of light-absorbing particles. Therefore, to avoid these artefacts, MAAP data have been compensated using the method described in Hyvärinen et al. (2013). A more detailed explanation can be found in Sect. 3.1.

The other instrument used to measure the $b_{\mathrm{abs}}$ is the Aethalometer model AE-31-ER (Magee Scientific). The AE31 measures light attenuation at seven different wavelengths ( $\lambda$ ) covering the UV $(370 \mathrm{~nm})$, visible $(470,520,590$, and $660 \mathrm{~nm}$ ), and NIR (880 and $950 \mathrm{~nm})$ ranges. A complete description of the operating principles of Aethalometers can be found in Hansen (2005).

The Aethalometer measures the light attenuation through a quartz filter matrix as aerosols are deposited on the filter. This parameter is defined by

$\operatorname{ATN}(\lambda)=-\ln \left(\frac{I(\lambda)}{I_{0}(\lambda)}\right)$,

where $I$ is the intensity of light that passes though the particle-loaded part of the filter, and $I_{0}$ is the intensity of light passing through the unloaded part of the filter. The attenuation coefficient $\left(b_{\mathrm{ATN}}\right)$ at each wavelength can be obtained by

$b_{\mathrm{ATN}}(\lambda)=\frac{A}{V} \frac{\Delta \mathrm{ATN}(\lambda)}{\Delta t}$,

where $A$ is the filter spot area $\left(1.67 \mathrm{~cm}^{2}\right), V$ the flow rate, and $\triangle \mathrm{ATN}$ is the variation in the attenuation measured during the time interval $\Delta t$. The attenuation coefficient is determined from the change of attenuation and is therefore due entirely to the loading of the filter by aerosols. In this work the instrument was operated with a flow rate of $4 \mathrm{~L} \mathrm{~min}^{-1}$ and a sampling interval of $5 \mathrm{~min}$. The compensation algorithm to obtain $b_{\mathrm{abs}}$ from $b_{\mathrm{ATN}}$ is described in more detail in Sect. 3.2.

Aerosol scattering $\left(b_{\text {scat }}\right)$ and backscattering $\left(b_{\mathrm{bsp}}\right)$ coefficients at ground level were measured using a TSI Model 3563 three-wavelength $(450,550,700 \mathrm{~nm})$ integrating nephelometer (Anderson et al., 1996; Heintzenberg et al., 2006). This instrument draws the ambient air through a temperaturemonitored inlet at a flow rate of $30 \mathrm{~L} \mathrm{~min}^{-1}$, illuminates the sample with a halogen lamp, and measures the scattered light using three photomultiplier tubes. The scattered light is integrated over an angular range which can be adjusted to either $7-170^{\circ}$ or $90-170^{\circ}$, using a backscatter shutter to give total scatter and backscatter signals. Pressure and temperature are measured in the sample chamber, so scattering by air molecules can be calculated and then subtracted from the total scattering to determine scattering by aerosol particles. In our case, although no drying of the aerosol stream was performed, the relative humidity measured within the nephelometer chamber was low with a mean value of $28 \pm 10 \%$. Thus, we can consider that the hygroscopic growth does not affect our measurements. In this study, non-idealities due to truncation errors were corrected (Anderson and Ogren, 1998). Uncertainties in the nephelometer measurements consist of angular truncation errors, non-Lambertian nature of the light source, and wavelength non-idealities. The calibration uncertainty is approximately $7 \%$ (Anderson et al., 1996; Anderson and Ogren, 1998; Esteve et al., 2012).

\section{Data compensation and methods}

All filter absorption photometers are affected by loading effects which need to be compensated, and the various compensation methods relied mostly on the continuity of data (Weingartner et al., 2003; Virkkula et al., 2007; Hyvärinen et al., 2013) to derive the compensation parameters. Here we propose a more robust method to determine the quality of the compensation for loading effects: the slope of the absorption coefficient vs. the loading of the spot. This method was used to compensate the BC measurements (Park et al., 2010), but here we use it as an independent criterion to evaluate the compensation. This criterion does not use any assumptions or external data, only the measurements from a single instrument - it checks the measured parameters for internal consistency. For a long period of homogeneous measurements in terms of the sources and meteorology, the absorption coefficient should not depend on the loading of the spot. The uncompensated measurements of $\mathrm{BC}$ in filter photometers are proportional to the time derivative of the attenuation of detected light intensity (MAAP: in reflection; Aethalometer: in transmission), not on the absolute attenuation values. Any dependence of the measured absorption on the loading (attenuation) is evidence of a bias due to the loading of the spot. The parameter, which was shown to be most representative of these effects, is the slope of the attenuation or absorption coefficient or as a function of the loading (following the logic in Park et al., 2010). We will demonstrate the usefulness of this method as an independent criterion of the compensation for both absorption photometers used in the study - the MAAP and the Aethalometer AE-31 - by plotting the average value of the attenuation or absorption coefficient as a function of the loading of the spot with BC.

\subsection{MAAP compensation}

Hyvärinen et al. (2013) observed that at high BC concentrations the MAAP measurements are also affected by artefacts which are different to those seen in other filter-based instruments, such as the PSAP or the Aethalometer. Two solutions were proposed to avoid or compensate for this problem: either applying a compensation algorithm to the $b_{\text {atn }}$ given directly by the MAAP's internal algorithm or using reflectance signal only, as obtained from the photodetector at $165^{\circ}$, which was found to be relatively free of this artefact, 


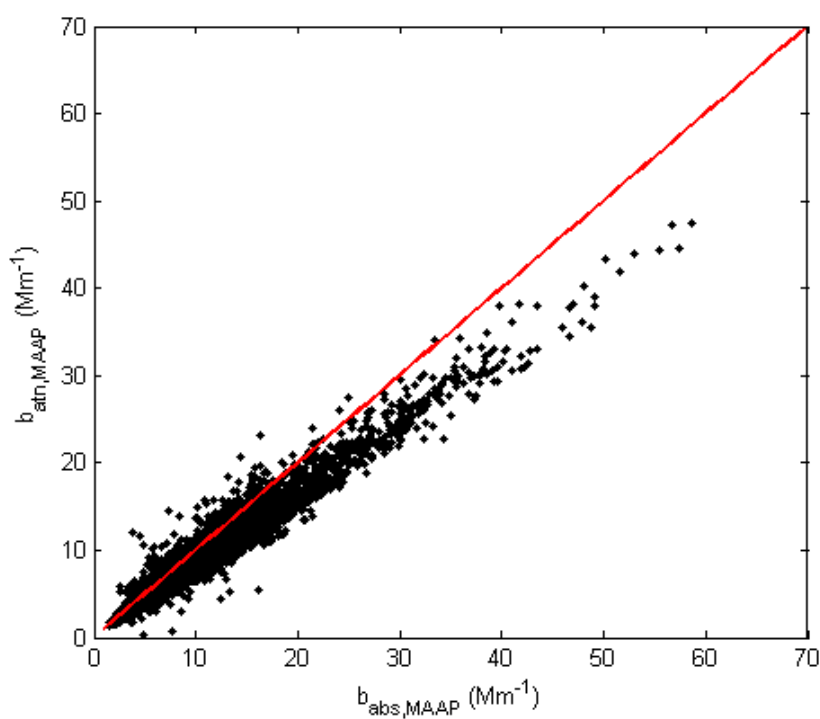

Figure 1. Non-compensated absorption coefficient ( $\left.b_{\text {atn, MAAP }}\right)$ vs. compensated absorption coefficient obtained from the reflected signal ( $b_{\text {abs, MAAP }}$ ), showing the relationship between the $b_{\text {atn, MAAP }}$ given by the MAAP, as explained in Sect. 2.2, and the compensated $b_{\text {abs, MAAP }}$ obtained with the reflected signal at $165^{\circ}$.

albeit exhibiting more scatter and not completely eliminating the artefact jump at the tape advance (Hyvärinen et al., 2013).

In this work, the MAAP was set to give the photodetector raw signals as an output, so the reflected signal at $165^{\circ}$ was chosen to obtain the absorption coefficient at $637 \mathrm{~nm}$. The attenuation coefficient given by the MAAP $\left(b_{\text {atn, MAAP }}\right)$ can be determined from the reflected signals by using the following equation (Petzold et al., 2005):

$b_{\text {atn }, \mathrm{MAAP}}=0.5 \frac{A}{V} \ln \left(\frac{R_{0}}{R}\right)$,

where, in our case, $\left(R_{0} / R\right)$ is the ratio of the photodetector signal at $165^{\circ}$ for a particle-free to a particle-loaded filter, $A$ is the filter spot area $\left(2 \mathrm{~cm}^{2}\right)$, and $V$ is the sampled volume. The multiplication factor of 0.5 in Eq. (3) has to be applied because the light passes through the layer of sampled aerosol twice before reaching the photodetector.

The value obtained from Eq. (3) does not correspond to the absorption coefficient since there is a filter-loading effect which influences the measured signals. Petzold et al. (2005) determined an empirical method to compensate this artefact using test aerosols. These test aerosols consisted of pure black aerosol samples from kerosene flame particles, and externally mixed grey and black aerosols of varying singlescattering albedo. The obtained relation for the aerosol absorption coefficient for these aerosols using the reflected signal is

$b_{\text {abs, MAAP }}=b_{\text {atn, MAAP }}\left(0.226+1.415 \frac{R}{R_{0}}\right)^{-1}$
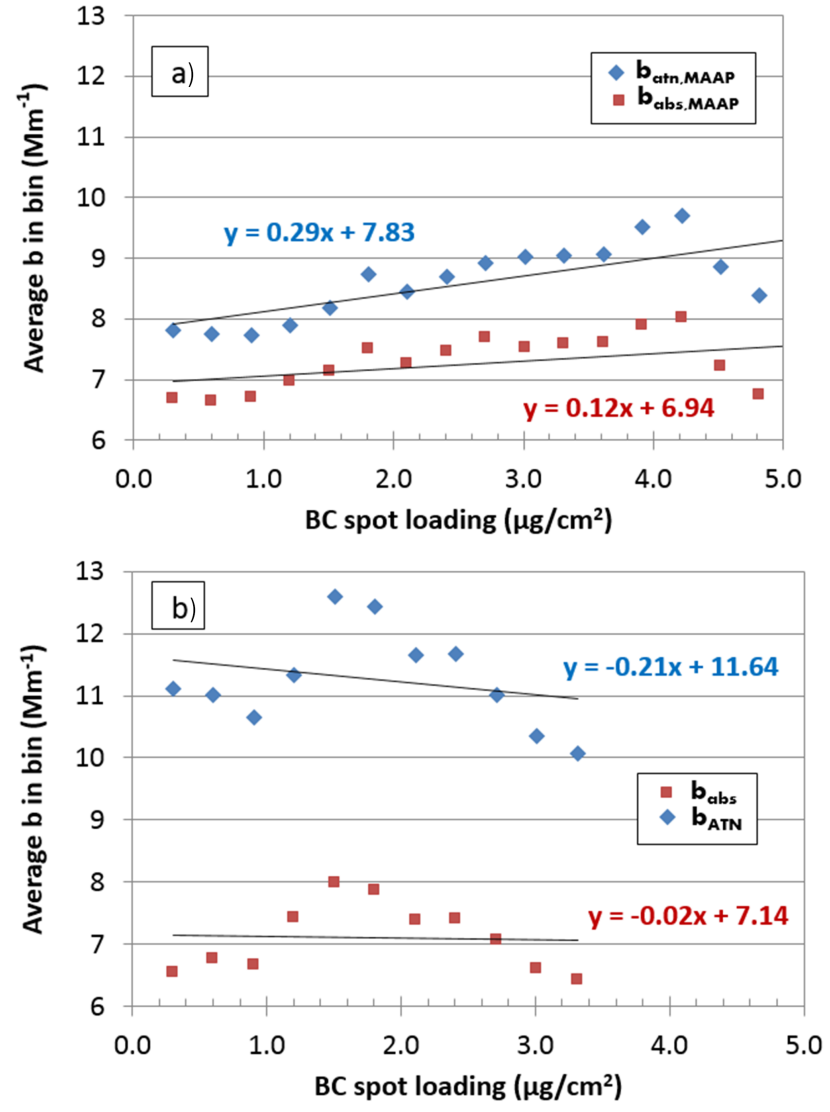

Figure 2. Average attenuation and absorption coefficient vs. loading of the spot: (a) the non-compensated MAAP attenuation coefficient $b_{\text {atn,MAAP }}$ and the compensated (Eq. 4) MAAP absorption coefficient $b_{\mathrm{abs}}$ MAAP, and (b) the Aethalometer attenuation coefficient $b_{\text {ATN }}$ and the compensated (Eq. 7) Aethalometer absorption coefficient $b_{\text {abs }}$.

Similar to Hyvärinen et al. (2013), values automatically provided by the MAAP are lower than those calculated from raw reflected signal for high absorption coefficients $\left(b_{\text {abs,MAAP }}\right)$ (Fig. 1). We do not observe any systematic saturation in the measurements as found previously (Kanaya et al., 2008) or large discontinuities in the data at the tape advance (Brito et al., 2013). This indicates that the use of the reflection signals rather than the default values compensated the data successfully. To check the compensation, we plot (Fig. 2a) the average value of the MAAP attenuation and absorption coefficient in a spot-loading bin (with width $0.3 \mu \mathrm{g} \mathrm{cm}^{-2}$ ) as a function of the loading of the spot with $\mathrm{BC}$ between a clean filter (no loading) and the $\mathrm{BC}$ value with enough data in the campaign to gather enough statistics (just above $5 \mu \mathrm{g} \mathrm{cm}^{-2}$ ). The slope of the compensated MAAP absorption coefficient is half of that of the uncompensated ones, proving that the compensation reduces the loading effects. Another feature which is informative is the intercept of the fit: this is the uncompensated MAAP attenuation coefficient $\left(7.83 \mathrm{Mm}^{-1}\right.$; Fig. $\left.2 \mathrm{a}\right)$ or the compensated absorption 
coefficient $\left(6.94 \mathrm{Mm}^{-1}\right.$; Fig. 2b) characteristic for the campaign. We propose to use the difference between the intercept $6.94 \mathrm{Mm}^{-1}$ (that is, the compensated absorption coefficient, representative for the campaign) and the campaign average absorption coefficient $7.25 \mathrm{Mm}^{-1}$ as an additional internal criterion for the "efficiency of compensation" with an empirical limit of $5 \%$. The compensation of the MAAP data using the reflection measurements, rather than the raw MAAP data, satisfies this criterion, and we use the compensated MAAP absorption coefficient for comparison with the Aethalometer attenuation and absorption coefficients.

\subsection{Aethalometer}

\subsubsection{Data pre-processing}

The Aethalometer raw data were first screened with three criteria: data showing excessive noise, and the upper and lower limits of the Aethalometer detection. High noise in the measurements degrades the determination of the absorption spectral dependence. This wavelength dependence can be approximated by a power-law expression (Ångström, 1929). A measurement is considered too noisy if the curve cannot fit a spectrum satisfactorily (Rizzo et al., 2011); therefore, only fits with $R^{2}$ higher than 0.85 have been chosen to reduce noise. The same data treatment was applied to the nephelometer data as well.

The second criterion is related to the lower detection limit of the instrument, as the measured attenuation should be above it. According to the Aethalometer manual, this limit corresponds to a mass increase of $5 \mathrm{ng}$ and can be expressed in units of the $b_{\mathrm{abs}}\left(\mathrm{Mm}^{-1}\right)$ by the following expression:

$\min \left(b_{\mathrm{abs}}\right)=\frac{m \cdot \sigma_{\mathrm{ATN}}(\lambda)}{\Delta t \cdot V}$,

where $m=5 \mathrm{ng}, \sigma_{\mathrm{ATN}}(\lambda)$ is the mass-specific attenuation cross section in $\mathrm{m}^{2} \mathrm{~g}^{-1}, \Delta t$ is the time-based period (set to $5 \mathrm{~min}$ in our case), and $\mathrm{V}$ is the sampling flow in $\mathrm{L} \mathrm{min}^{-1}$ ( $4 \mathrm{~L} \mathrm{~min}^{-1}$ in our instrument). The attenuation cross section is calculated using the following equation:

$\sigma_{\mathrm{ATN}}=\frac{14625}{\lambda[\mathrm{nm}]}$.

This equation is based on a calibration at $880 \mathrm{~nm}$ using the Malissa-Novakov method, a solvent-based thermal desorption method for elemental carbon analysis (Gundel et al., 1984).

Also, as a consequence of random voltage fluctuations and from recording discontinuities which take place during the Aethalometer's tape advance, a third criterion related to the upper detection limit is applied (De Castro et al., 2008). To identify these low-quality data, the 99th percentile of the attenuation coefficient (i.e. $162.2 \mathrm{Mm}^{-1}$ at $660 \mathrm{~nm}$ ) was chosen as the extreme upper limit.
From the whole data set, $4 \%$ of the data did not satisfy any of these three criteria, leaving a total number of 8276 measurements.

\subsubsection{Data compensation}

Aethalometer artefacts, unlike MAAP artefacts, are well known and five different algorithms have been proposed to compensate them (Weingartner et al., 2003; Arnott et al., 2005; Schmid et al., 2006; Virkkula et al., 2007; CollaudCoen et al., 2010). The light beam crossing the filter suffers (1) multi-scattering effects due to the filter fibres; (2) single-scattering effects, due to the aerosol particles deposited in the filter; and (3) filter-loading effects, which are related to the shadowing produced as the particles accumulate on the filter. The result of these optical interactions is that $b_{\text {ATN }}$ is generally larger than $b_{\text {abs }}$ (Petzold et al., 1997; Ballach et al., 2001).

Due to the aforementioned aerosol-filter interactions, the Aethalometer requires specific site compensation factors. In this sense, we have calculated these compensation factors for our site and used them to compensate the Aethalometer data by applying the algorithms proposed by Weingartner et al. (2003) and Schmid et al. (2006). The reason to select these two algorithms, out of the five existing ones, is that Weingartner et al. (2003) and Schmid et al. (2006) found a way to obtain the spectral dependence of the multiple-scattering compensation factor from aerosol single-scattering albedo. Knowing this spectral dependence will allow us to convert $b_{\text {ATN }}$ to $b_{\text {abs }}$ for all seven Aethalometer wavelengths. The most important difference between these two algorithms lies in the fact that Weingartner's algorithm does not consider the artefact produced by the single-scattering effect, while Schmid's does.

In their test with ammonium sulfate, Weingartner et al. (2003) found no significant dependence of $b_{\mathrm{ATN}}$ on the scattering component of the aerosol in the filter. Therefore, they proposed an algorithm to obtain $b_{\text {abs }}$ without taking into account the single-scattering effect of the aerosols:

$b_{\mathrm{abs}}=\frac{b_{\mathrm{ATN}}}{C \cdot R(f, \mathrm{ATN})}$,

where $C$ is the parameter describing the enhancement of absorption particles in the filter matrix and compensates for the multiple-scattering effects exhibiting values $\geq 1$ and $R(f$, ATN) for the loading effect with values $\leq 1$. The loading compensation depends on the amount of the sample collected on the filter and is hence dependent on the attenuation measured by the Aethalometer. The parameter can be expressed as proposed in Weingartner et al. (2003):

$R(f, \mathrm{ATN})=\left(\frac{1}{f}-1\right) \frac{\ln \mathrm{ATN}-\ln 10 \%}{\ln 50 \%-\ln 10 \%}+1$,

where $f$ is the shadowing factor, which depends on the type of the aerosols. This parameter has been calculated by minimizing the difference between the ratio of $b_{\mathrm{ATN}}$ before and 
Table 1. Compensation factors obtained for the seven Aethalometer wavelengths: $f$ corresponds to the "shadowing effect" in the loading compensation; $100 \mathrm{~m}_{\mathrm{s}}$ is the value given in Arnott et al. (2005) to the scattering fraction of particles; $C_{\text {Arnott }}^{*}$ is the value given in Arnott et al. (2005) to the multiple-scattering compensation factor ( $C^{*}$ in Schmid et al., 2006, and in this work); $C^{*}$ and $C$ are the values specifically site-calculated in this work.

\begin{tabular}{lrrrrrrr}
\hline \multicolumn{7}{c}{ Spectral compensation factors } \\
\hline$\lambda(\mathrm{nm})$ & 370 & 470 & 520 & 590 & 660 & 880 & 950 \\
$f$ & 1.204 & 1.141 & 1.120 & 1.093 & 1.084 & 1.044 & 1.041 \\
$100 m_{\mathrm{S}}$ & 3.35 & 4.57 & 5.23 & 6.16 & 7.13 & 10.38 & 11.48 \\
$C_{\text {Arnott }}^{*}$ & 1.813 & 2.073 & 2.076 & 2.104 & 2.182 & 2.226 & 2.199 \\
$C^{*}$ & 3.26 & 3.72 & 3.73 & 3.78 & 3.92 & 3.99 & 3.95 \\
$C$ & 3.42 & 3.87 & 3.90 & 3.98 & 4.19 & 4.35 & 4.59 \\
\hline
\end{tabular}

after the filter spot change. The calculated median $f$ values were plotted as a function of $\lambda$ and fitted with a linear equation (Sandradewi et al., 2008b). Values obtained for this parameter are shown in Table 1.

The effect of the compensation of the Aethalometer measurements is shown in Fig. 2b. The slope reduces significantly to a value which is non-distinguishable from $0-$ the compensation is efficient in eliminating the loading effects. The difference between the intercept $7.14 \mathrm{Mm}^{-1}$ (the compensated absorption coefficient, representative for the campaign) and the campaign average absorption coefficient $7.10 \mathrm{Mm}^{-1}$ satisfies the empirical $5 \%$ criterion. Additionally, the value lies extremely close to the average and the intercept determined from the analysis of the MAAP compensation (Sect. 3.1).

Since the loading effect is small for lightly loaded filters (Weingartner et al., 2003), $C$ can be determined by comparing low loaded Aethalometer measurements (ATN < 10\%) with the ones obtained by a different comparison instrument. In this study we compared the Aethalometer-derived absorption coefficient with $b_{\mathrm{abs}, \mathrm{MAAP}}$ from the MAAP, and $C$ is determined using the equation proposed in Weingartner et al. (2003) as

$C=\frac{b_{\mathrm{ATN}}(\mathrm{ATN}<10)}{b_{\mathrm{abs}, \mathrm{MAAP}}}$.

$C$ has been calculated at $637 \mathrm{~nm}$, as the MAAP measurements are performed at this wavelength. Since the nearest wavelengths in the Aethalometer are 590 and $660 \mathrm{~nm}, b_{\text {ATN }}$ $(637 \mathrm{~nm})$ has been calculated by approximating the wavelength dependence of the attenuation spectra for each measurement to a power-law expression, such as

$b_{\mathrm{ATN}}(\lambda)=a \cdot \lambda^{-\alpha_{\mathrm{atn}}}$,

where $a$ is a fitting parameter and $\alpha_{\text {atn }}$ is the Angström exponent of attenuation.

After taking logarithm of Eq. (10), a "linear fit" was applied to the log-log curve:

$\ln \left[b_{\mathrm{ATN}}(\lambda)\right]=\ln a-\alpha_{\mathrm{atn}} \ln (\lambda)$.
To calculate $C, b_{\mathrm{ATN}}$ at $637 \mathrm{~nm}$ for the Aethalometer data has to be calculated since $b_{\text {abs, MAAP in Eq. (9) is related to }}$ $637 \mathrm{~nm}$. The average $C$ value at the wavelength of $637 \mathrm{~nm}$ $\left(C_{637}\right)$ was determined to be $C_{637}=4.22 \pm 0.06$ from the arithmetic mean (95\% confidence level of the mean) of the

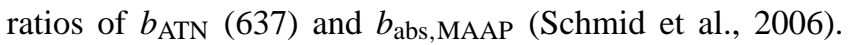
Collaud-Coen et al. (2010) obtained different $C$ values ranging between 2.8 and 7.8 at several sites. In particular, from the different sites chosen in that paper, our value is close to those obtained $\left(C=4.12 \pm 0.06\right.$ at $\left.660 \mathrm{~nm}, C_{660}\right)$ at Cabauw (the Netherlands), a background site located near populated and industrialized areas (Collaud-Coen et al., 2010).

Some publications (Lack et al., 2009; Nakayama et al., 2010) indicate that the multiple-scattering compensation factor might depend on the particle size, as the aerosol penetration depth into the filter varies depending on the size. Since this effect is still difficult to quantify (Rizzo et al., 2011), it is not straightforward to conclude if there will be an overestimation or underestimation in our absorption coefficients due to this effect. A significant part of the aerosol loading on the filter tape on the measurement site is always diesel exhaust particles, so at least this part of the loading is extremely homogeneous. Therefore, we did not consider this effect further in this manuscript.

\subsubsection{Spectral dependence of $C$ and Aethalometer absorption coefficients}

Schmid et al. (2006) parameterized (based on Arnott et al., 2005) the spectral dependence of $C$ using the following expression:

$C(\lambda)=C^{*}(\lambda)+m_{\mathrm{s}}(\lambda) \frac{\omega_{0}(\lambda)}{1-\omega_{0}(\lambda)}$,

where $C^{*}$ is the multiple-scattering compensation factor, which includes the effects of aerosol scattering; $m_{\mathrm{s}}$ is the fraction of the aerosol scattering coefficient erroneously interpreted as absorption; $\omega_{0}$ is the aerosol single-scattering albedo; and $\lambda$ is the wavelength. Both $C^{*}(\lambda)$ and $m_{\mathrm{s}}$ were calculated for ammonium sulfate particles by Arnott et al. (2005). They however showed that these values gave unsatisfactory results when used to correct ambient measurements.

Equation (12) has been used to obtain $C^{*}$ at $637\left(C_{637}^{*}\right)$ using $C_{637}$ calculated in the previous section with Eq. (9). Once it is calculated, $C^{*}$ values for the other wavelengths will be obtained assuming the same wavelength dependence as in Arnott et al. (2005). Values of $m_{\mathrm{S}}$ used here were taken from Arnott et al. (2005) since with our data it is not possible to determine them. $\omega_{0}(637)$ was calculated using the following expression (Schmid et al., 2006):

$\omega_{0}(637)=\frac{b_{\text {scat }}(637)}{b_{\text {scat }}(637)+b_{\text {abs, MAAP }}(637)}$,

where $b_{\text {abs,MAAP }}$ (637) is the MAAP absorption coefficient measured at $637 \mathrm{~nm}$ and $b_{\text {scat }}(637)$ is the scattering 
coefficient from the nephelometer, interpolated to $637 \mathrm{~nm}$ by using Eqs. (10) and (11) for $b_{\text {scat }}(\lambda)$.

To obtain the different $C$ values for the remaining Aethalometer wavelengths, $\omega_{0}(\lambda), C^{*}(\lambda)$, and $m_{\mathrm{s}}(\lambda)$, are required (Eq. 12). Equation (13) is not useful in this case since MAAP absorption is only obtained at one wavelength and cannot be applied for the other Aethalometer channels. Therefore, for calculating $\omega_{0}(\lambda)$ we used the following expression (Schmid et al., 2006):

$$
\omega_{0}(\lambda)=\frac{\omega_{0, \text { ref }}\left(\frac{\lambda}{\lambda_{\text {ref }}}\right)^{-\alpha_{\text {scat }}}}{\omega_{0, \text { ref }}\left(\frac{\lambda}{\lambda_{\text {ref }}}\right)^{-\alpha_{\text {scat }}}+\left(1-\omega_{0, \text { ref }}\right)\left(\frac{\lambda}{\lambda_{\text {ref }}}\right)^{-\alpha_{\text {abs }}}},
$$

where $\omega_{0, \text { ref }}$ is the reference single-scattering albedo calculated at $637 \mathrm{~nm}\left(\lambda_{\text {ref }}\right)$ using Eq. (13), $\alpha_{\text {scat }}$ is the Ångström exponent of scattering, and $\alpha_{\mathrm{abs}}$ is the Ångström exponent of absorption. $\alpha_{\text {scat }}$ depends on the $b_{\text {scat }}$ measured at different wavelengths and can be obtained from the nephelometer measurements $(450-700 \mathrm{~nm})$. However, $\alpha_{\mathrm{abs}}$ is calculated from the $b_{\text {abs }}$ measured by the Aethalometer at different wavelengths.

Schmid et al. (2006) used fixed values for $\alpha_{\text {scat }}$ calculated using wavelengths $450-700\left(\alpha_{\text {scat } 450-700}\right)$ and $\omega_{0}(545)$ measurements given by Chand et al. (2006) for Amazonia, and a range of different $\alpha_{\text {abs }}$ based on Kirchstetter et al. (2004) to obtain a parameterization function of $C(\lambda)$ and $\alpha_{\text {abs. Then }}$ they applied an iterative procedure over this function to obtain $C(\lambda)$ and $\alpha_{\text {abs. }}$. The fixed values used were $\alpha_{\text {scat }}=$ $2.0 \pm 0.4$ and $\omega_{0}(532)=0.92 \pm 0.02$, which differ from our values in Granada during July $2012, \alpha_{\text {scat }, 450-700}=1.3 \pm 0.3$ and $\omega_{0}(637)=0.76 \pm 0.08$, consistent with the prevalence of diesel traffic on the highway near the measurement site. These differences between both sites are significant and make the parameterization function of $C(\lambda)$ given by Schmid et al. (2006) not applicable to our measurements. Therefore, based on their work, the iterative procedure has been used to calculate $\alpha_{\text {abs }}$ and, then, $C(\lambda)$ and $b_{\text {abs }}(\lambda)$, following these steps:

1. The Ångström exponent of attenuation $\left(\alpha_{\text {atn }}\right)$ is calculated by fitting the logarithm of the spectral attenuation coefficients with a linear fit as presented in Eq. (11).

2. The $\alpha_{\mathrm{atn}}$ is used in Eq. (14) as a first estimation of $\alpha_{\mathrm{abs}}$, to obtain $\omega_{0}(\lambda)$, and then the compensation factor $C$ for each Aethalometer wavelength is calculated using Eq. (12).

3. The compensation factor $C(\lambda)$ at different wavelengths is used in Eq. (7) to obtain the new compensated absorption coefficients $\left(b_{\mathrm{abs}}\right)$.

4. This new $b_{\text {abs }}(\lambda)$ is used again in step 1 to get a better estimation for $\alpha_{\mathrm{abs}}$.

5. Repeat steps 2-4 until $\alpha_{\text {abs }}$ converges with a precision of 0.005 .
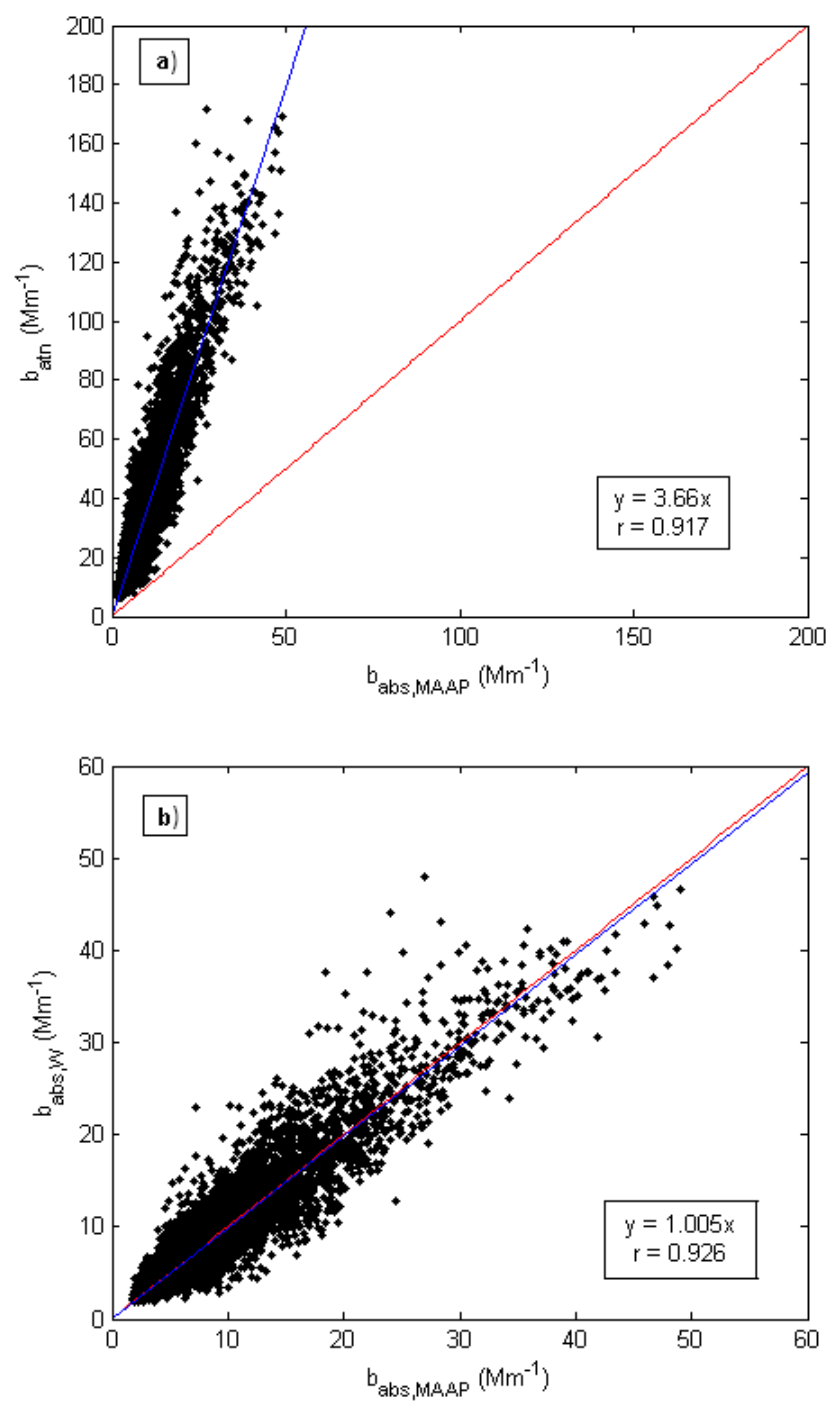

Figure 3. Comparison of the Aethalometer vs. MAAP absorption coefficient $\left(b_{\mathrm{abs}, \mathrm{MAAP}}\right)$ at $637 \mathrm{~nm}$ for (a) non-compensated Aethalometer data $\left(b_{\mathrm{ATN}}\right)$ and (b) Weingartner's compensation $\left(b_{\mathrm{abs}, \mathrm{W}}\right.$.

\section{Results of the compensations}

\subsection{Non-compensated/compensated Aethalometer vs. MAAP data}

In Fig. 3a, non-compensated Aethalometer data $\left(b_{\mathrm{ATN}}\right)$ at $637 \mathrm{~nm}$ obtained using Eq. (11) are compared to $b_{\mathrm{abs}, \text { MAAP }}$ values. The Aethalometer and the MAAP are well correlated, with $R=0.917$, while the slope of 3.66 shows the relationship between the Aethalometer attenuation coefficient and the MAAP absorption.

After Weingartner's compensation (Weingartner et al., 2003) is applied to the Aethalometer attenuation coefficient, we obtain the compensated Aethalometer absorption coefficient, which is represented as $b_{\mathrm{abs}, \mathrm{W}}$ in this section to 
Table 2. Statistics of MAAP and Aethalometer compensated and non-compensated absorption coefficients at $637 \mathrm{~nm}$ : mean standard error, standard deviation, median, maximum, minimum, 25 th percentile, and 95th percentile. MAAP corresponds to $b_{\mathrm{abs}}$,MAAP statistics; $b_{\mathrm{ATN}}$ corresponds to non-corrected Aethalometer data; $b_{\mathrm{abs}, \mathrm{W}}$ corresponds to data compensated as proposed by Weingartner et al. (2003); and $b_{\text {abs, Arnott }}$ represents data compensated with the algorithm and compensation factors ( $M$ and $\alpha$ ) from Arnott et al. (2005).

\begin{tabular}{lrrrrrrr}
\hline$b_{637}\left(\mathrm{Mm}^{-1}\right)$ & Mean \pm SE & SD & Median & Minimum & Maximum & P25 & P95 \\
\hline$b_{\text {abs,MAAP }}$ & $9.15 \pm 0.07$ & 5.8 & 7.7 & 1.76 & 49.0 & 5.3 & 20.2 \\
$b_{\text {ATN }}$ & $34.0 \pm 0.2$ & 21.5 & 28.7 & 6.37 & 171.5 & 19.7 & 76.0 \\
$b_{\text {abs, W }}$ & $9.35 \pm 0.07$ & 6.1 & 7.8 & 1.87 & 48.0 & 5.3 & 21.3 \\
$b_{\text {abs, Arnott }}$ & $17.84 \pm 0.13$ & 11.6 & 14.8 & 3.56 & 91.5 & 10.1 & 40.6 \\
\hline
\end{tabular}

highlight that it has been obtained using Weingartner's compensation. The slope between $b_{\mathrm{abs}, \mathrm{W}}$ and $b_{\mathrm{abs}, \mathrm{MAAP}}$ changes to 1.005 and there appears a slight increase of the correlation coefficient: from 0.917 to 0.926 (Fig. 3b). The compensation factors used $\left(C_{637}=4.22 \pm 0.06\right.$ and $\left.f_{637} \approx f_{660}=1.131\right)$ were already obtained in Sect. 3.2.2. Dispersion of some points is due to some noise in the data which has not been removed by the filtration algorithm described above in Sect. 3.2.1. We can further reduce this dispersion by averaging the data over a more extended period of time. Furthermore, the compensated $b_{\mathrm{abs}, \mathrm{W}}$ values are on average $73 \%$ lower than corresponding non-compensated $b_{\mathrm{ATN}}$ values and differ from $b_{\text {abs,MAAP }}$ on average by around $2 \%$.

The statistics of the comparison between the two data sets are shown in Table 2. Average values of $b_{\text {abs, MAAP }}$ and $b_{\text {abs, W }}$ with their standard deviations are $9.2 \pm 5.8$ and $9.4 \pm 6.1 \mathrm{Mm}^{-1}$, respectively. The 25 th and 95 th percentile for both data sets are very similar, indicating a similar distribution of the data. The statistical analysis shows a good agreement between $b_{\mathrm{abs}, \mathrm{MAAP}}$ and $b_{\mathrm{abs}, \mathrm{W}}$. Therefore it is concluded that Weingartner's compensation, with our sitespecific compensation parameters, compensates satisfactorily the Aethalometer $b_{\mathrm{ATN}}$ to obtain absorption coefficients which agree well with those measured by the MAAP.

\subsection{Compensation parameters at different wavelengths and final compensation}

The spectral dependence of $C$ can be obtained using Eq. (12). To start, $C^{*}$ and $m_{\mathrm{s}}$ as proposed in Arnott et al. (2005) for $660 \mathrm{~nm}$ were used (see Table 2). The $C_{660}$ value of 2.21 was obtained, which is only $\sim 50 \%$ of the value obtained at $637 \mathrm{~nm}$ (see previous Sect. 3.2.2). Applying this compensation factor leads to unsatisfactory comparison with $b_{\text {abs, MAAP, }}$ since the new compensated data ( $b_{\text {abs, Arnott }}$ ) overestimate the MAAP data (slope of 1.92). The statistics of the comparison of these two data sets are shown in Table 2 as $b_{\mathrm{abs}, \text { Arnott }}$. These results corroborate that the $C^{*}$ and $m_{\mathrm{s}}$ parameter values from Arnott et al. (2005) are not applicable for this campaign. To get a better estimation of the spectral dependence on $C$, specific ambient measurements were calculated to obtain $C^{*}(\lambda)$. As we only have available $C_{637}$ for the direct comparison of the two absorption photome- ters, $C_{637}^{*}$ can be calculated by using Eq. (12) and assuming $m_{\mathrm{S}}(637) \approx m_{\mathrm{s}}(660)=0.0713$ (Table 1$)$. The value obtained is 3.93, which differs from the value obtained by Arnott et al. (2005) in the laboratory ( $C_{\text {Arnott }}^{*}$ of 2.182 at $660 \mathrm{~nm}$ ), as can be seen in Table 1. On the other hand, this value is consistent with their proposal of $C^{*}(521)=3.69$ for ambient measurements. Following this, $C^{*}(\lambda)$ values at other wavelengths have been calculated assuming the same spectral dependence of $C_{\text {Arnott }}^{*}(\lambda)$ given by Arnott et al. (2005) and normalized to $C_{\text {Arnott }}^{*}(660)$. As can be seen from Table 1, the obtained $C^{*}(\lambda)$ are much higher than those estimated by Arnott et al. (2005) or by Weingartner et al. (2003) in the laboratory.

Once we had retrieved the $C^{*}(\lambda)$ values, the iterative method explained in Sect. 3.2.3 was applied for each measurement to calculate the $C(\lambda)$, which will be used to compensate $b_{\text {ATN }}(\lambda)$. Almost $93 \%$ of the data converges at the fourth iteration, while the remaining $7 \%$ does at the fifth iteration. The averaged values for $C(\lambda)$ are shown in Table 1 . It is evident that $C$ increases with $\lambda$, from 3.42 in the UV $(370 \mathrm{~nm})$ channel to 4.59 in the infrared $(950 \mathrm{~nm})$. Comparing these values with our reference $C_{637}$, calculated using Eq. (9), a higher wavelength dependence is observed at lower wavelengths $(\sim 23 \%$ for $C$ at $370 \mathrm{~nm})$ than at nearinfrared wavelengths ( $\sim 4 \%$ for $C$ at $950 \mathrm{~nm})$. Weingartner et al. (2003) assumed that there was no wavelength dependence on $C$ since the difference in their measurements between 450 and $660 \mathrm{~nm}$ was smaller than $10 \%$. This is consistent with our data since the difference in $C$ between 470 and $660 \mathrm{~nm}$ is $\approx 8 \%$, and the only wavelength differing more is $370 \mathrm{~nm}$ (see Table 1). Furthermore, the differences in our calculated $C$ values at each wavelength are similar to the ones reported in Schmid et al. (2006) for $\alpha_{\mathrm{abs}} \approx 1$. In addition, the average $\alpha_{\text {abs }}$ obtained with the iterative method was found to be 1.09 with a standard deviation of around 0.25. We performed a sensitivity analysis on the effect of the compensation on the $C$ values: a $15 \%$ change of the parameter $f$ causes a change in the $C$ values smaller than $1 \%$ for all wavelengths.

The obtained $b_{\text {abs }}$ are, on average, around 72 and $79 \%$ lower than the corresponding $b_{\mathrm{ATN}}$ values measured at 370 and $950 \mathrm{~nm}$, respectively. Rizzo et al. (2011) reported a decrease of $75 \%$ at $450 \mathrm{~nm}$, which is similar to the findings in 

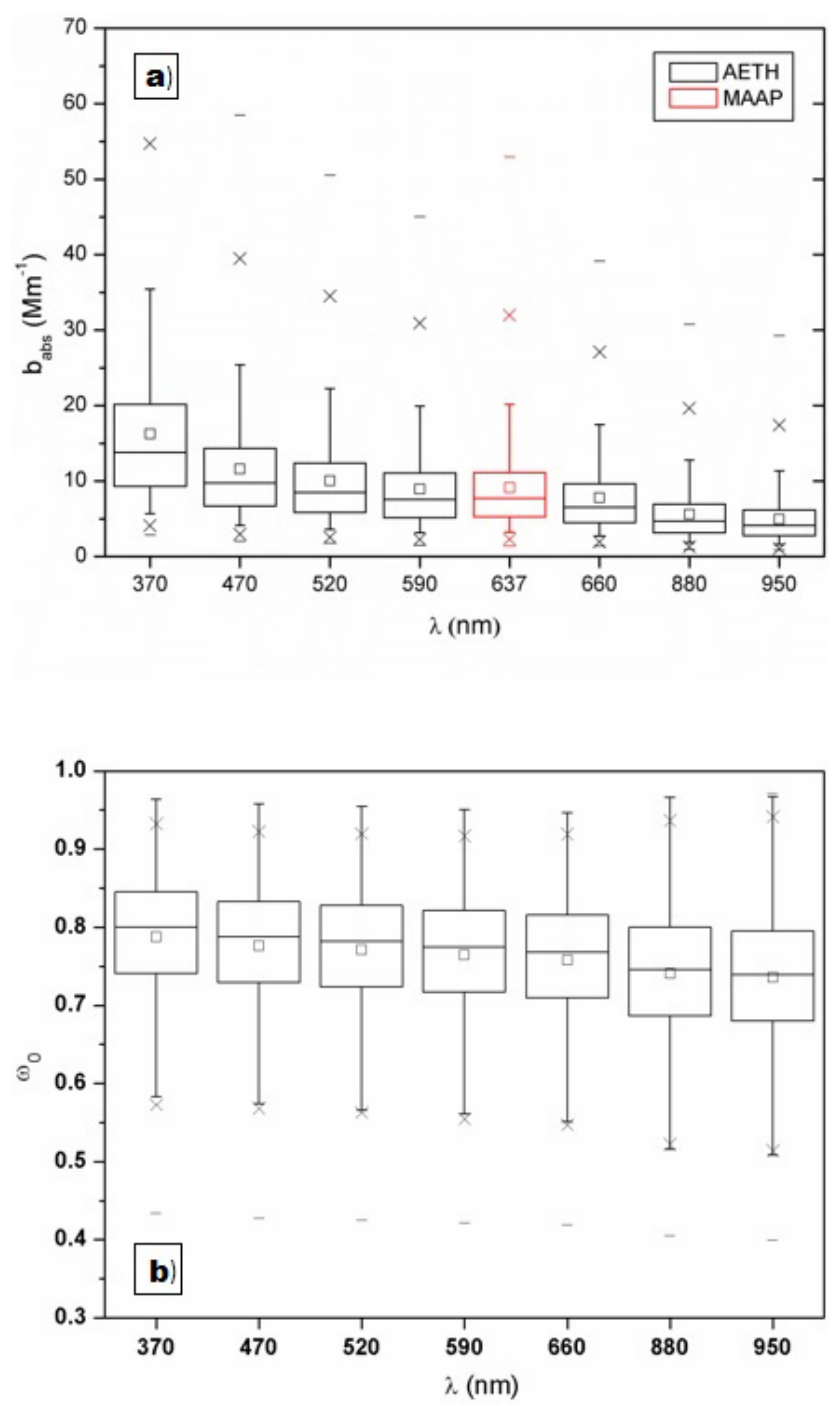

Figure 4. Whisker boxplot of (a) the Aethalometer (black) and MAAP (red) compensated absorption coefficients $\left(b_{\text {abs }}\right)$ and (b) single-scattering albedo $\left(\omega_{0}\right)$ for the seven aethalometer channels. The square inside the boxes represents the average; the central line corresponds to the median; the edges of the box are the 25th and 75th percentiles; the whiskers correspond to 5th and 95th percentiles; and horizontal lines outside the boxes correspond to maxima and minima.

this study. Figure 4 shows a boxplot of the compensated absorption coefficients $b_{\text {abs }}$ at each wavelength obtained from the Aethalometer and the MAAP. On one hand, it can be seen that the MAAP absorption coefficient is in reasonable agreement with the boxes from the compensated Aethalometer data at 590 and $660 \mathrm{~nm}$. This is expected when the data are properly compensated, since the spectral behaviour of the absorption coefficient follows a power law as shown in Eq. (10).

Rizzo et al. (2011) performed sensitivity tests and showed that the main source of error due to $b_{\text {abs }}$ and $\alpha_{\text {abs }}$ is driven by the choice of $\alpha_{\text {scat }}$. Since they used averaged values over the whole measurement period, their sensitivity tests consisted in varying these values and seeing how this affected the final result for $b_{\text {abs }}$ and $\alpha_{\text {abs }}$. They obtained a maximum deviation in the results of \pm 10 and $\pm 40 \%$ on $b_{\mathrm{abs}}$ and $\alpha_{\mathrm{abs}}$, respectively. Following their tests, in our measurements, only $\pm 1 \%$ for $b_{\text {abs }}$ and $\pm 2 \%$ for $\alpha_{\text {abs }}$ deviations are observed. This is due to the fact that we have used concurrent absorption and scattering measurements at multiple wavelengths and have thus reduced deviations in $b_{\mathrm{abs}}$ and $\alpha_{\mathrm{abs}}$ significantly.

\section{Spectral absorption coefficient, spectral single-scattering albedo, and Ångström exponent of absorption}

\subsection{Temporal evolution of aerosol spectral properties}

The statistics for $\omega_{0}$ obtained for the seven Aethalometer channels were calculated (Fig. 4b). Averaged $\omega_{0}$ values from 370 to $950 \mathrm{~nm}$ lie between 0.78 and 0.74 , with a standard deviation of 0.08-0.09. Lyamani et al. (2010) reported an average value of $\omega_{0}$ at $670 \mathrm{~nm}$ of $0.73 \pm 0.06 \mathrm{in}$ summer, which is close to the value obtained in this work, $\omega_{0}$ at $660 \mathrm{~nm}$ of $0.76 \pm 0.08$. In general, the $\omega_{0}(\lambda)$ average values show that during the measurement period the atmosphere in Granada at surface level contained a large fraction of absorbing particles.

Figure 5 shows the temporal evolution of hourly and daily averaged data for the different optical aerosol parameters calculated in the previous section during the period from 29 June to 29 July. Figure $5 \mathrm{a}$ and $\mathrm{b}$ display the hourly and daily average values of $\omega_{0}(\lambda)$ obtained for the 370 and $950 \mathrm{~nm}$ channels of the Aethalometer. In Fig. 5a it can be observed that the $\omega_{0}$ minima of $0.5-0.6$ correspond to maximum peaks of $b_{\mathrm{abs}}$ (Fig. 5d). These maxima in $b_{\mathrm{abs}}$ are a consequence of traffic emissions; this suggests that lower values of $\omega_{0}$ are caused by traffic emissions which increase the absorbing component at surface level (Lyamani et al., 2010, 2011). During the whole period $\omega_{0}$ at $950 \mathrm{~nm}$ is higher than $\omega_{0}$ at $370 \mathrm{~nm}$, except for ordinal days 181 (29 June) and 202203 ( 20 and 21 July). A more detailed analysis of these days will be discussed below.

In the case of the $\alpha_{\mathrm{abs}}$ (Fig. 5c), except for the mentioned special episodes, values of this parameter show pointto-point variations no greater than 0.1 . Hourly average values of $\alpha_{\text {abs }}$ are mostly between 0.9 and 1.2. The spectral dependence of $b_{\mathrm{abs}}$ does not vary a lot, nor does the daily average of $\alpha_{\mathrm{abs}}$, which exhibits values around 1.1 for most of the month. Values of $\alpha_{\text {abs }}$ around 1 are related to the presence of traffic aerosols (Sun et al., 2007) and are typical of urban areas (Bergstrom et al., 2007). This corroborates the fact that the site in Granada is dominated by urban aerosols whose major source is traffic (Lyamani et al., 2008, 2010; Titos et al., 2012). Maxima are greater than 1.55 (P95) and reach values up to 2.5. These high values are related to special aerosol episodes (dust and biomass burning 

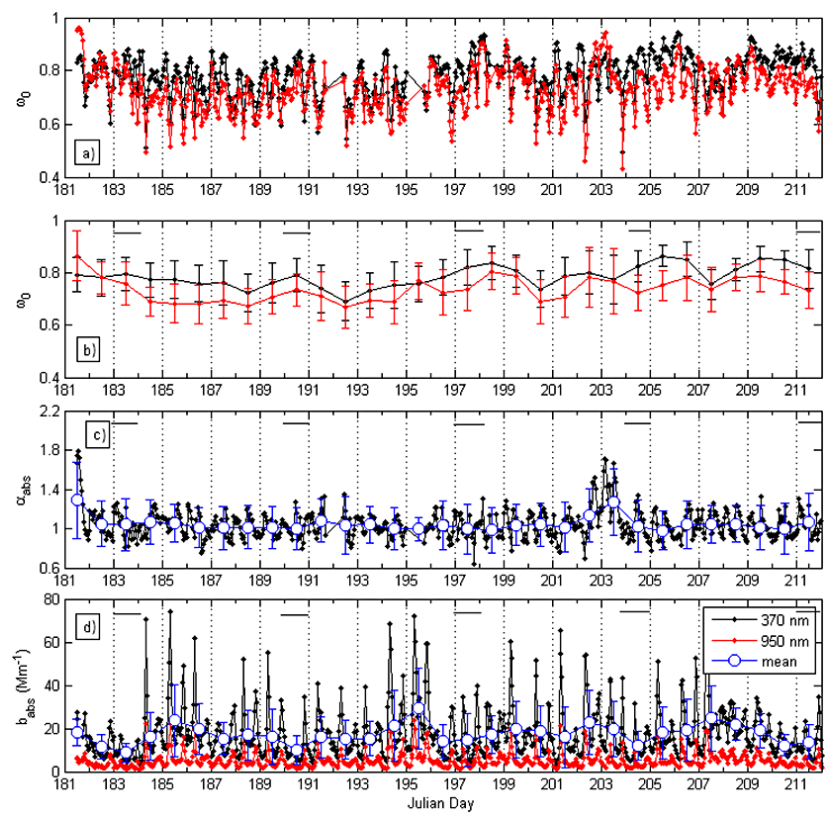

Figure 5. Temporal evolution of: (a) $\omega_{0,370}$ and $\omega_{0,950}$ hourly averaged, (b) $\omega_{0,370}$ and $\omega_{0,950}$ daily averaged, (c) $\alpha_{\text {abs }}$ hourly (black line) and daily averaged (blue dots), and (d) $b_{\mathrm{abs}, 370}$ and $b_{\mathrm{abs}, 950}$ hourly averaged and daily averaged values for $b_{\mathrm{abs}, 370}$ (blue dots) with their standard deviations. Black lines correspond to hourly averages at $370 \mathrm{~nm}$ and red lines to hourly averages at $950 \mathrm{~nm}$, except for $\alpha_{\mathrm{abs}}$ and panel (b), where they correspond to daily averages. All these data correspond to the period June-July 2012.

particles) affecting Granada during the measurement period, which will be described in more detail below.

Figure $5 \mathrm{~d}$ shows the hourly average values of the $b_{\mathrm{abs}}$ at 370 and $950 \mathrm{~nm}$. Both channels exhibit very similar temporal behaviour, although absorption coefficients in the UV are considerably higher than those in the near infrared. The same evolution is seen for $b_{\mathrm{abs}}$ at the other five channels, with values located between these two channels (not shown). Averaged values obtained for the compensated $b_{\mathrm{abs}}$ range between 16 (at $370 \mathrm{~nm}$ ) and $5 \mathrm{Mm}^{-1}$ (at $950 \mathrm{~nm}$ ) with standard deviations of 10 and $3 \mathrm{Mm}^{-1}$, respectively (Fig. 4a).

For the two events already mentioned - ordinal days 181 (29 June) and 202-203 (20 and 21 July) - an extended analysis of surface level characteristics was made using back trajectories and results from the Navy Aerosol Analysis and Prediction System (NAAPS, http://www.nrlmry. navy.mil/aerosol/). The model used for calculating back trajectories is the Hybrid Single-Particle Lagrangian Integrated Trajectory Model (HYSPLIT) developed by the National Oceanic and Atmosphere Administration (Draxler and Rolph, 2003). On the other hand, the NAAPS model is a global model that predicts concentrations of sulfates, dust and smoke aerosols at ground level and in the atmospheric column (Christensen, 1997). Measurements of a Raman lidar operated at Granada station (Guerrero-Rascado et al.,

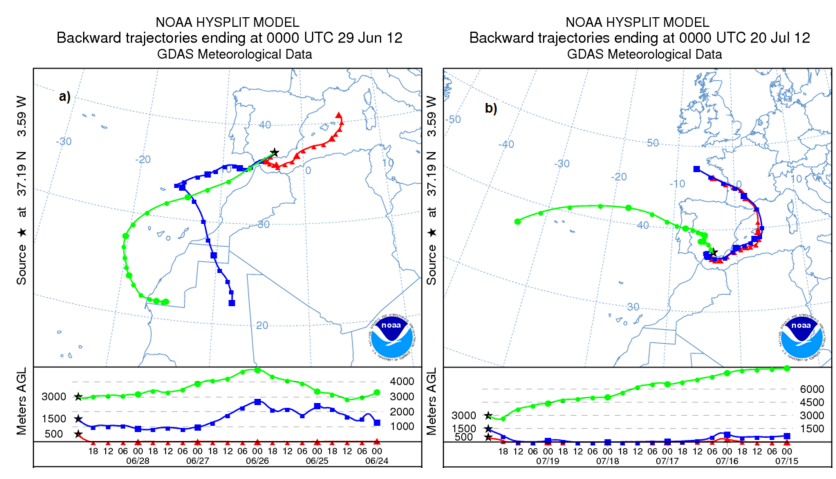

Figure 6. Five-day back trajectories from HYSPLIT at three different heights (500 (red), 1500 (blue), and $3000 \mathrm{~m}$ (green) a.g.1.) for (a) 29 June and (b) 20 July.

2008) and included in EARLINET (European Aerosol Research Lidar Network; Boesenberg et al., 2001) were used to support the interpretation of the data. Images of the temporal evolution of the lidar range-corrected signal (RCS) can be consulted online at http://atmosfera.ugr.es/inv/index.php/en/ quicklooks.html.

Figure 6 shows the five-day back trajectories arriving at Granada on 29 June and 20 July 2012. Figure 7 shows the concentration of different types of particles (dust, biomass smoke) at ground level predicted by the NAAPS model for 29 June and 20 July at 12:00 and 18:00 UTC. On 29 June, the trajectories arriving at 1500 and $3000 \mathrm{~m}$ a.g.l. came from the western Sahara, while the trajectory at $500 \mathrm{~m}$ a.g.l. came from the Mediterranean Sea between Spain and northern Africa (Fig. 6a). In addition, from Fig. 7a it can be seen that on 29 June NAAPS predicted a significant surface concentration of dust particles $\left(80-160 \mu \mathrm{g} \mathrm{m}^{-3}\right)$ at Granada. Furthermore, no significant contributions from biomass burning and sulfate aerosols were obtained from the NAAPS model. Figure 8a shows the temporal evolution of the lidar RCS at $532 \mathrm{~nm}$ on 29 July. Early in the morning the presence of an aerosol layer decoupled from the planetary boundary layer is evident. The analysis of the backward trajectories suggests that the decoupled layer extending from 2000 to $3000 \mathrm{~m}$ a.s.1. originated in northern Africa. This is clear evidence of the Saharan dust outbreak over our station.

To study whether there is any noticeable effect in the optical properties at ground level or not, the $24 \mathrm{~h}$ average values of both $\omega_{0}(\lambda)$ and $b_{\mathrm{abs}}(\lambda)$ obtained on 29-30 June and 20 21 July are shown in Fig. 9a and b, respectively. Figure 9a shows a strong spectral dependence of $\omega_{0}(\lambda)$ on 29 June with considerably lower values $(\sim 0.80)$ for the UV channel than in the IR, which is a well-known characteristic of dust. On 30 June, the spectral dependence of $\omega_{0}(\lambda)$ is not strong, and can be related to the fact that the dust intrusion is over and urban aerosols are dominant again. Collaud-Coen et al. (2004) proposed a method for detecting Saharan dust events based on the change of the Ångström exponent of single-scattering 


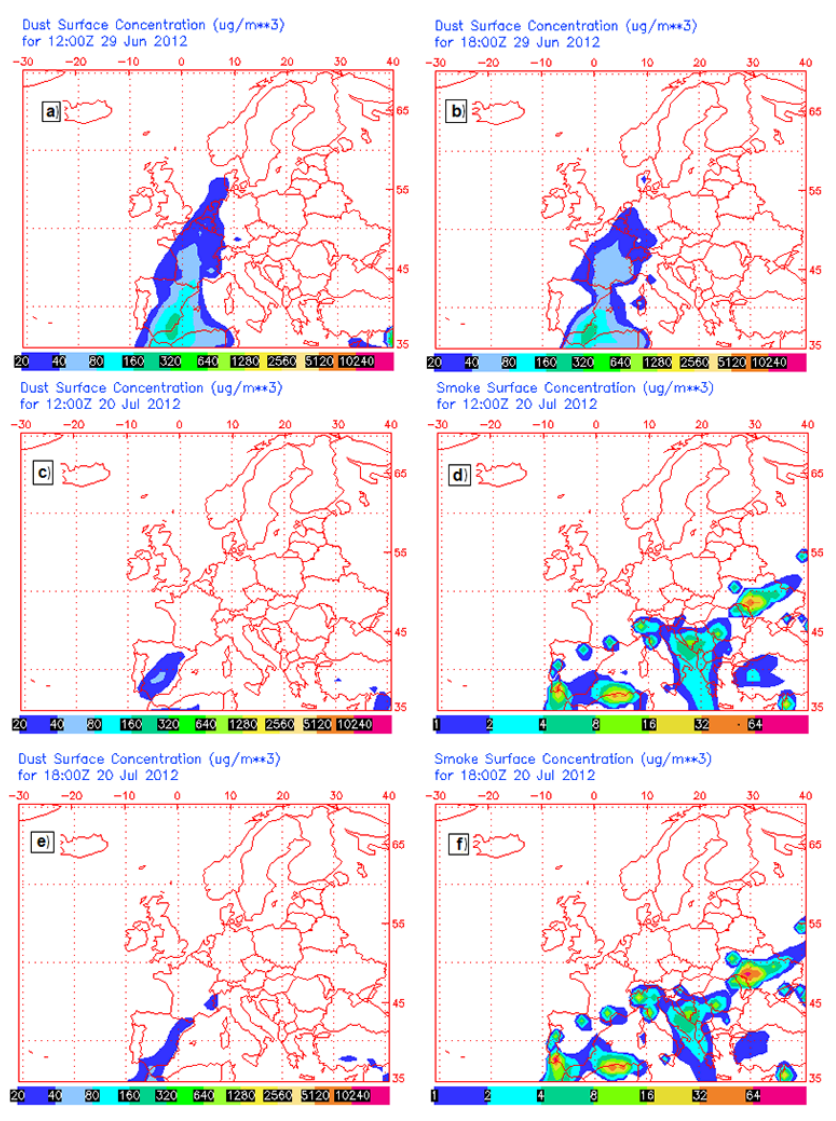

Figure 7. Total surface dust and biomass burning concentration predicted by the NAAPS model for 29 June at (a) 12:00 UTC and (b) 18:00 UTC, (c, d) 20 July 12:00 UTC, and (e, f) 20 July 18:00 UTC. Biomass burning concentration is only shown for 20 July since on 29 June there were no concentrations of this type over Granada.

albedo $\left(\alpha_{\mathrm{SSA}}\right)$. Negative exponent values of the $\alpha_{\mathrm{SSA}}$ are due to the large size of mineral aerosols. In our case, on 29 June a $\alpha_{\mathrm{SSA}}=-0.09$ is obtained, which is related to the presence of dust in the atmosphere. On 30 June this wavelength dependence decreased to $\alpha_{\mathrm{SSA}}=-0.007$, indicating that the mineral dust intrusion was over. In the case of the $b_{\mathrm{abs}}(\lambda)$ a stronger spectral dependence for the values obtained on 29 than for 30 June is found (Fig. 9b). This spectral dependence leads to the values of $\alpha_{\mathrm{abs}}$ of 1.34 and 1.09 on 29 and 30 June, respectively. The return of the exponent to a value close to 1 is consistent with diesel aerosols becoming predominant again. Figure 5c shows that the $\alpha_{\text {abs }}$ reached values up to nearly 2.0 during the dust intrusion on 29 June. To study the consistency of the $\alpha_{\text {abs }}$ values obtained during this dust event, they were compared with those obtained in other studies. Collaud-Coen et al. (2004) reported $\alpha_{\text {abs }}$ values between 1.5 and 1.8 during Saharan dust events at Jungfraujoch, as well as a non-negligible spectral dependence of $\omega_{0}$. Values of $\alpha_{\text {abs }}$ of 2.2 were reported by Bergstrom et al. (2002) for mixed urban pollution and desert dust aerosols in ACEAsia (Aerosol Characterization Experiment). Therefore, it can be concluded that our determination of the Saharan dust episodes and the associated values of the Angström exponent of single-scattering albedo are in good agreement with the published values.

Another event was detected on 20 (day 202) and 21 (day 203) July. HYSPLIT back trajectories arriving on 21 July at 500 and $1500 \mathrm{~m}$ a.g.l. reached Granada proceeding from the Mediterranean Sea, along northern Africa's coast, although they have their origin in western France. At $3000 \mathrm{~m}$ a.g.l. they originate from the Atlantic Ocean (Fig. 6b). NAAPS predictions, presented in Fig. $7 \mathrm{~b}$ and $\mathrm{c}$, show influence of both dust and smoke aerosols at surface level on 20 July. The temporal evolution of RCS at $532 \mathrm{~nm}$ obtained from lidar measurements (Fig. 8b) shows the presence of aerosol particles up to $4000 \mathrm{~m}$ a.s.l., and especially high concentrations are measured up to $2000 \mathrm{~m}$ a.s.l. Based on the NAAPS model and lidar measurements, aerosols measured at surface level are considered to be affected by wood smoke and mineral dust.

Values on 20 July were daily averaged starting at 12:00 UTC, when the event is first detected. The analysis of the wavelength dependence of $\omega_{0}$ leads to $\alpha_{\mathrm{SSA}}=-0.08$ on 20 July, showing again presence of dust, and to $\alpha_{\mathrm{SSA}}=-0.011$ on $21 \mathrm{July}$, when the episode is over. In Fig. 9a a stronger spectral dependence of $\omega_{0}$ during the event is observed. Similar to the event on 29 July, variations in the spectral dependence indicate a change in the dominant source and origin of the aerosols which is corroborated with NAAPS predictions of dust and smoke aerosols at surface level. Figure $9 \mathrm{~b}$ shows that the spectral dependence of $b_{\mathrm{abs}}$ does not show significant differences from one day to another; the values of $\alpha_{\mathrm{abs}}$ are 1.28 and 1.31 for 20 and 21 July, respectively.

Although there are similarities in the spectral dependencies of the optical parameters, the two events differ: on 29 June the event is dominated by dust with larger $\omega_{0}$ and lower $b_{\text {abs }}$; on 20 and 21 July the aerosol is a mixture of smoke and dust, with lower $\omega_{0}$ and higher $b_{\text {abs }}$.

\subsection{Comparison between workdays and Sundays}

In Fig. 5d, based on the daily averages (blue dots), it was already observed that $b_{\text {abs }}$ was generally higher during workdays than on Sundays. Due to these differences, the hourly average values in UTC of $\omega_{0}$ at 370 and $950 \mathrm{~nm}, b_{\text {abs }}$ at 370 and $950 \mathrm{~nm}$, and $\alpha_{\text {abs }}$ have been calculated for workdays (Monday to Friday) and Sundays (Fig. 10).

In Fig. 10a it can be seen that during daytime $\omega_{0}$ is in general slightly higher on Sundays than workdays. At nighttime, $\omega_{0}$ values are very similar, the difference being only 0.05 . The fact that a less absorptive atmosphere is found on weekends than on workdays results directly from the $b_{\text {abs }}$ behaviour. During the daytime, $b_{\text {abs }}$ for workdays is considerably higher than during Sundays (Fig. 10b), which also causes lower $\omega_{0}$ from Monday to Friday. It is also seen that on workdays and Sundays $b_{\text {abs }}$ has two maxima, one in the morning (between 04:00 and 09:00) and another in 

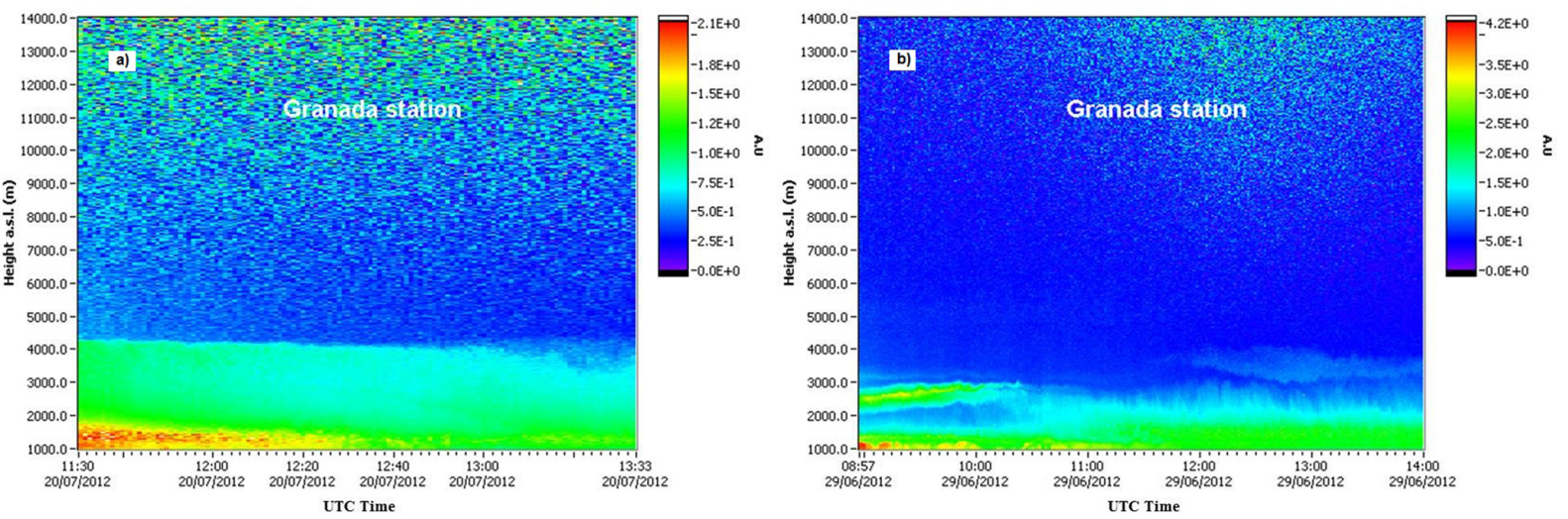

Figure 8. Lidar vertical profiles obtained for (a) 29 June from 08:57 to 14:00 UTC and (b) 20 July 11:30 to 13:30 UTC.
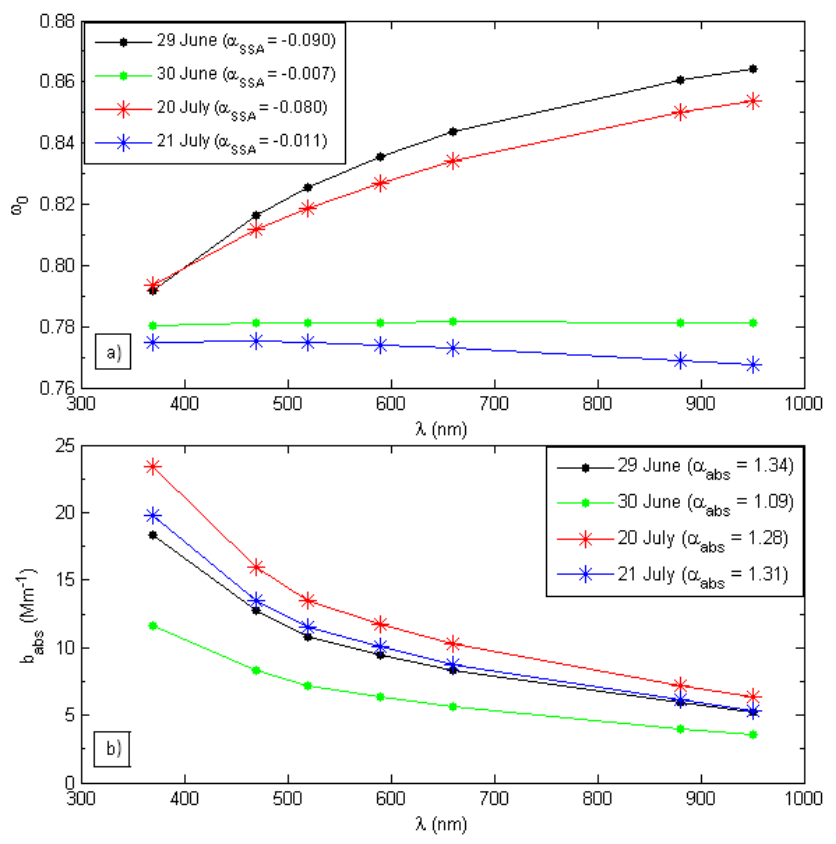

Figure 9. Spectral dependence of daily averaged (a) $\omega_{0}$ and (b) $b_{\text {abs }}$ for 29 June (black), 30 June (green), 20 July (red), and 21 July (blue).

the afternoon (between 18:00 and 21:00). Those maxima are strongly related to minima in $\omega_{0}$. Usually, the morning $b_{\mathrm{abs}}$ maximum is considerably higher on workdays than on Sundays due to its relation with traffic volume, which is more intense from Monday to Friday. This causes a more pronounced decrease in $\omega_{0}$ during the workdays. On the other hand, the evening maximum appears to be very similar for workdays and Sundays.

The diurnal variation of the exponent $\alpha_{\text {abs }}$ shows no important differences between workdays and Sundays. Unlike $\omega_{0}$, this parameter appears to be not affected by maxima in $b_{\text {abs }}$. This corroborates the fact that $\alpha_{\mathrm{abs}}$ is a parameter related to
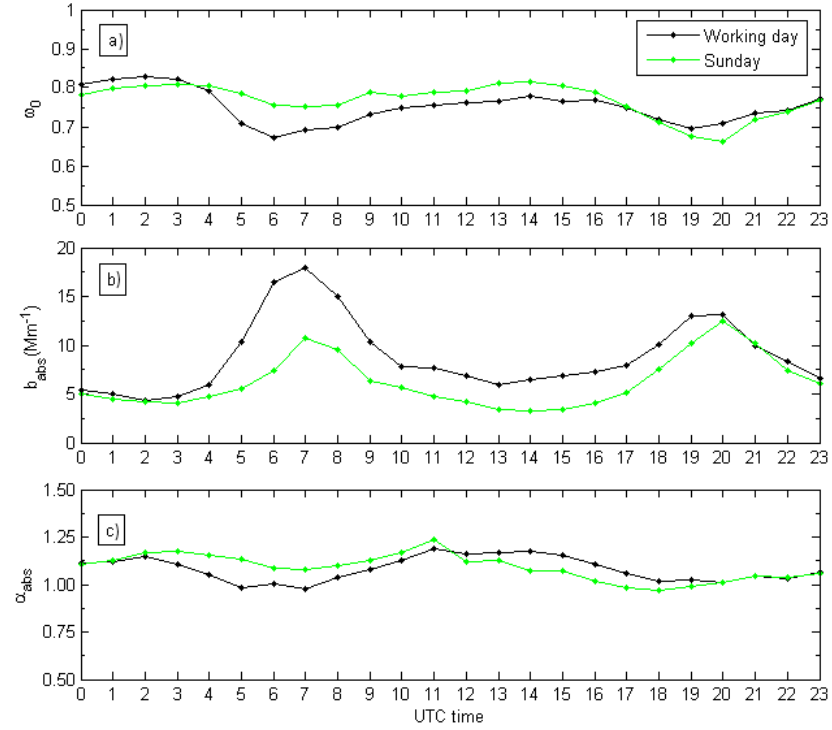

Figure 10. Comparison of average during cycles for workdays (black) and Sundays (green) of: (a) single-scattering albedo $\left(\omega_{0,660}\right)$, (b) absorption coefficient $\left(b_{\mathrm{abs}, 660}\right)$, and (c) $\alpha_{\mathrm{abs}}$.

the type of absorbing particles and their source rather than to their concentration.

\section{Conclusions}

The aim of this study has been to obtain the compensated absorption coefficient for all seven Aethalometer AE31 channels, generalizing the method proposed by Schmid et al. (2006). Once the Aethalometer coefficients have been compensated, the temporal evolution of $\omega_{0}(\lambda), b_{\mathrm{abs}}(\lambda)$, and $\alpha_{\mathrm{abs}}(\lambda)$ was analysed. In addition, during the measurement period two different sources of aerosolized particulate matter affecting Granada were investigated, and the differences between workdays and Sundays were presented. 
The attenuation coefficient at $637 \mathrm{~nm}$ was compensated applying the method proposed by Weingartner et al. (2003) and then compared to $b_{\text {abs }}$ obtained from MAAP measurements. Furthermore, site-specific parameters for the loading $(R(f, \mathrm{ATN}))$ and multiple scattering $(C)$ were obtained. The values for the loading parameter $(f)$ range from 1.15 at $370 \mathrm{~nm}$ to 1.11 at $950 \mathrm{~nm}$, which is consistent with previous values reported by Weingartner et al. (2003), Sandradewi et al. (2008b), and Collaud-Coen et al. (2010), among others. Compensated data from both instruments were checked for any remaining loading effects, and none were found.

For the multiple-scattering effect, the $C$ value at $637 \mathrm{~nm}$ was found to be $4.22 \pm 0.06$, and it is in agreement with values published in the literature for sites with similar characteristics. Results of the comparison with the MAAP give a slope of 1.005 and a correlation coefficient of 0.926 . Therefore, the compensated factors obtained in this study provide a satisfactory compensation of the data and are used to calculate the $C$ factor at other wavelengths.

To obtain the wavelength dependence of $C(\lambda)$, the additional parameters $m_{\mathrm{s}}$ and $C^{*}$ are needed, which were obtained by Arnott et al. (2005) in laboratory experiments. These values proved to be quite low when applied to ambient measurements, so new $C^{*}(\lambda)$ values were calculated in this study. The $C^{*}$ value for ambient data calculated at $637 \mathrm{~nm}$ for this campaign exhibits a value of 3.93, while the $m_{\mathrm{S}}$ used is the value provided by Arnott et al. (2005). Differences in $C^{*}$ agree with those expected from Arnott et al. (2005) for ambient measurements. The same spectral dependence as in Arnott et al. (2005) has been used to obtain $C^{*}$ at other wavelengths.

Applying the iterative procedure proposed by Schmid et al. (2006), $C(\lambda), \omega_{0}(\lambda)$, and $\alpha_{\text {abs }}$ using wavelengths from 370 to $950 \mathrm{~nm}$ were calculated. $C$ values obtained span from 3.42 at $370 \mathrm{~nm}$ to 4.59 at $950 \mathrm{~nm}$, and their spectral differences are in agreement with the ones observed in Schmid et al. (2006) for the Amazon Basin.

Once the different parameters had been compensated and calculated at each wavelength, a study of their temporal evolution was performed. Averaged values of $\omega_{0}$ range between 0.784 (at $370 \mathrm{~nm}$ ) and 0.737 (at $950 \mathrm{~nm}$ ), indicating that during July 2012 Granada's atmosphere was significantly burdened with absorbing particles. This is in agreement with results obtained by Lyamani et al. (2010) for the summer period. An average value of 1 for $\alpha_{\mathrm{abs}}$ is explained by the fact that the Granada site is dominated by urban aerosols (Sun et al., 2007) whose major source is traffic.

Finally, the difference between workdays and Sundays shows that the absorption coefficients are higher during workdays than during Sundays as a consequence of the traffic intensity on the highway close to the station. These values cause decreases in $\omega_{0}$, leading to an atmosphere with more absorbing particles during the workdays. However, $\alpha_{\mathrm{abs}}$ is not affected and exhibits no differences between work days and Sundays as this value is more related to the aerosol type and their source, which does not strongly change at this site.

Acknowledgements. The authors gratefully acknowledge the NOAA Air Resources Laboratory (ARL) for the provision of the HYSPLIT transport and dispersion model and/or READY website used in this publication. Also, we acknowledge the Naval Research Laboratory for providing the NAAPS data on their website. This work was financed jointly by the Spanish Ministry of Economy and Competitiveness and the European Regional Development Fund through projects CGL2011-24290, CGL2010-18782, CSD2007-00067, and CGL2012-33294; by the Valencia Autonomous Government through project PROMETEO/2010/064; the Andalusia Regional Government through projects P08-RNM-3568 and P10-RNM-6299; and by the Slovenian Ministry of Economic Development and Technology JR-KROP grant 3211-11-000519. The research leading to these results has received funding from the European Union Seventh Framework Programme (FP7/2007-2013) under grant agreement no. 262254 (ACTRIS). The collaboration of S. Segura in this work was possible thanks to fellowship BES-2010-031626.

Edited by: M. Rapp

\section{References}

Anderson, T. L. and Ogren, J. A.: Determining aerosol radiative properties using the TSI 3563 integrating nephelometer, Aerosol Sci. Tech., 29, 57-69, 1998.

Anderson, T. L., Covert, D. S., Marshall, S. F., Laucks, M. L., Charlson, R. J., Waggoner, A. P., Ogren, J. A., Caldow, R., Holm, R. L., and Quant, F. R., Sem, G. J., Wiedensohler, A., Ahlquist, N. A., and Bates, T. S.: Performance Characteristics of a High Sensitivity, Three-Wavelength, Total Scatter/Backscatter Nephelometer, J. Atmos. Ocean. Tech., 13, 967-986, 1996.

Ångström, A.: On the Atmospheric Transmission of Sun Radiation and on Dust in the Air, Geogr. Ann., 11, 156-166, 1929.

Arnott, W. P., Hamasha, K., Moosmuller, H., Sheridan, P. J., and Ogren, J. A.: Towards aerosol light-absorption measurements with a 7-wavelength aethalometer: Evaluation with a photoacoustic instrument and 3-wavelength nephelometer, Aerosol Sci Technol., 39, 17-29, 2005.

Ballach, J., Hitzenberger, R., Schultz, E., and Jaeschke, W.: Development of an improved optical transmission technique for black carbon (BC) analysis, Atmos. Environ., 35, 2089-2100, 2001.

Baron, P. A. and Willeke, K.: Aerosol Measurement: Principles, Techniques, and Applications, John Willey, Hoboken, N. J., 2005.

Bergstrom, R. W., Russell, P. B., and Hignett: Wavelength dependence of the absorption of black carbon particles: Predictions and results from the TARFOX experiment and implications for the aerosol single scattering albedo, Atmos. Sci., 59, 567-577, 2002.

Bergstrom, R. W., Pilewskie, P., Russell, P. B., Redemann, J., Bond, T. C., Quinn, P. K., and Sierau, B.: Spectral absorption properties of atmospheric aerosols, Atmos. Chem. Phys., 7, 5937-5943, doi:10.5194/acp-7-5937-2007, 2007. 
Boesenberg, J., Balis, D., Flamant, P., Papalardo, G., Papayanis, A., Pelon, J., Schneider, J., Trickl, T., Visconti, G.: in: EARLINET: A European Aerosol Research Lidar Network, Advances in Remote Sensing, edited by: Dabas, A., Flamant, P., and Pelon, J., Selected papers from the 20th International Laser Radar Conference, Vichy, France, 10-14 July, 2000, 155-158, 2001.

Bond, T. C. and Bergstrom: Light absorption by carbonaceous particles: an investigative review, Aerosol Sci. Tech., 40, 27-67, doi:10.1080/02786820500421521, 2006.

Bond, T. C., Anderson, T. L., and Campbell, D.: Calibration and intercomparison of filter-based measurements of visible light absorption by aerosols, Aerosol Sci. Technol., 30, 582-600, 1999.

Brito, J., Rizzo, L. V., Herckes, P., Vasconcellos, P. C., Caumo, S. E. S., Fornaro, A., Ynoue, R. Y., Artaxo, P., and Andrade, M. F.: Physical-chemical characterisation of the particulate matter inside two road tunnels in the São Paulo Metropolitan Area, Atmos. Chem. Phys., 13, 12199-12213, doi:10.5194/acp-1312199-2013, 2013.

Chand, D., Guyon, P., Artaxo, P., Schmid, O., Franck, G. P., Rizzo, L. V., Mayol-Bracero, O. L., Gatti, L. V., and Andreae, M. O.: Optical and physical properties of aerosols in the boundary layer and free troposphere over the Amazon Basin during the biomass burning season, Atmos. Chem. Phys., 6, 2911-2925, doi:10.5194/acp-6-2911-2006, 2006.

Christensen, J. H.: The Danish Eulerian hemispheric model - a three-dimensional air pollution model used for the artic, Atmos. Environ., 31, 4169-4191, 1997.

Collaud-Coen, M., Weingartner, E., Schaub, D., Hueglin, C., Corrigan, C., Henning, S., Schwikowski, M., and Baltensperger, U.: Saharan dust events at the Jungfraujoch: detection by wavelength dependence of the single scattering albedo and first climatology analysis, Atmos. Chem. Phys., 4, 2465-2480, doi:10.5194/acp4-2465-2004, 2004.

Collaud-Coen, M., Weingartner, E., Apituley, A., Ceburnis, D., Fierz-Schmidhauser, R., Flentje, H., Henzing, J. S., Jennings, S. G., Moerman, M., Petzold, A., Schmid, O., and Baltensperger, U.: Minimizing light absorption measurement artifacts of the Aethalometer: evaluation of five correction algorithms, Atmos. Meas. Tech., 3, 457-474, doi:10.5194/amt-3-457-2010, 2010.

De Castro, B. R., Wang, L., Mihalic, J. N., Breysse, P. N., and Geyh, A. S.: The Longitudinal Dependence of Black Carbon Concentration on Traffic Volume in an Urban Environment, Japca J. Air Waste Manage., 58, 928-393, 2008.

Draxler, R. R. and Rolph, G. D.: HYSPLIT (HYbrid Single-Particle Lagrangian Integrated Trajectory), Model access via NOAA ARL READY Website, available at: http://www.arl.noaa.gov/ ready/hysplit4.html, NOAA Air Resources Laboratory, Silver Spring, MD, 2003.

Dubovik, O., Holben, B., Eck, T. F., Smirnov, A., Kaufman, Y. J., King, M. D., Tanré, D., and Slutsker, I.: Variability of absorption and optical properties of key aerosol types observed in worldwide locations, Atmos. Sci., 59, 590-608, 2002.

Esteve, A. R., Estellés, V., Utrillas, M. P., and Martínez-Lozano, J. A.: In-situ integrating nephelometer measurements of the scattering properties of atmospheric aerosols at an urban coastal site in western Mediterranean, Atmos. Environ., 47, 43-50, 2012.
Fialho, P., Hansen, A. D. A., and Honrath, R. E.: A new approach to decouple dust and black carbon absorption coefficients using seven-wavelength Aethalometer data, J. Aerosol Sci., 36, 267282, 2005.

Guerrero-Rascado, J. L., Ruiz, B., and Alados-Arboledas, L.: Multispectral lidar characterization of the vertical structure of Saharan dust aerosol over southern Spain, Atmos. Environ., 42, 26682681, 2008.

Gundel, L. A., Dod, R. L., Rosen, H., and Novakov, T.: The relationship between optical attenuation and black carbon concentration for ambient and source particles, Sci. Total Environ., 36, 197202, 1984.

Hansen, A. D. A.: The Aethalometer TM. Magee Scientific Company, Berkeley, California, USA, available at: http://mageesci com/images/stories/docs/Aethalometer_book_2005.07.03.pdf (last access: August 2014), 2005.

Hansen, A. D. A., Rosen, H., and Novakov, T.: Real-time measurement of the absorption coefficient of aerosol particles, Appl Opt., 21, 3060-3062, 1982.

Hansen, A. D. A., Rosen, H., and Novakov, T.: The aethalometer; an instrument for the real-time measurements of optical absorption by aerosol particles, Sci. Total Environ., 36, 191-196, 1984.

Heintzenberg, J., Wiedensohler, A., Tuch, T. M., Covert, D. S., Sheridan, P. J., Ogren, J. A., Gras, J., Nessler, R., Kleefeld, C., Kalivitis, N., Aaltonen, V., Wilhelm, R.-T., and Havlicek, M.: Intercomparisons and aerosol calibrations of 12 commercial integrating nephelometers of three manufacturers, J. Atmos. Ocean. Tech., 23, 902-914, 2006.

Horvath, H: Atmospheric light absorption: a review, Atmos. Environ., 27, 293-317, 1993.

Houghton, J. T., Ding, Y., Griggs, D. J., Noguer, M., van der Linden, P. J., and Xiaosu, D.: Climate Change 2001: The Scientific Basis, Cambridge Univ. Press, New York, 2001.

Hyvärinen, A. P., Vakkari, V., Laakso, L., Hooda, R. K., Sharma, V. P., Panwar, T. S., Beukes, J. P., van Zyl, P. G., Josipovic, M., Garland, R. M., Andreae, M. O., Pöschl, U., and Petzold, A.: Correction for a measurement artifact of the Multi-Angle Absorption Photometer (MAAP) at high black carbon mass concentration levels, Atmos. Meas. Tech., 6, 81-90, doi:10.5194/amt-681-2013, 2013.

IPCC: in: Climate Change 2013, edited by: Stocker, T. F., Qin, D., Plattner, G.-K., Tignor, M., Allen, S. K., Boschung, J., Nauels, A., Xia, Y., Bex, V., and Midgley, P. M., The Physical Science Basis. Working Group I Contribution to the IPCC 5th Assessment Report - Changes to the underlying Scientific/Technical Assessment. Cambridge University Press, Cambridge, UK \& New York, USA, 2013.

Jacobson, M. Z.: Studying the effects of aerosol son vertical photolysis rate coefficient and temperature profiles over an urban air shed, J. Geophys. Res., 103, 10593-10604, 1998.

Kanaya, Y., Komazaki, Y., Pochanart, P., Liu, Y., Akimoto, H., Gao, J., Wang, T., and Wang, Z.: Mass concentrations of black carbon measured by four instruments in the middle of Central East China in June 2006, Atmos. Chem. Phys., 8, 7637-7649, doi:10.5194/acp-8-7637-2008, 2008.

Kirchstetter, T. W., Novakov, T., and Hobbs, P. V.: Evidence that the spectral dependence of light absorption by aerosols is affected by organic carbon, J. Geophys. Res., 109, D21208, doi:10.1029/2004JD004999, 2004. 
Lack, D. A., Cappa, C. D., Cross, E. S., Massoli, P., Ahern, A. T., Davidovits, P., and Onasch, T. B.: Absorption enhancement of coated absorbing aerosols: validation of the photo-acoustic technique for measuring the enhancement, Aerosol Sci. Technol., 43, 1006-1012, doi:10.1080/02786820903117932, 2009.

Lyamani, H., Olmo, F. J., and Alados-Arboledas, L.: Light scattering and absorption properties of aerosol particles in the urban environment of Granada, Spain, Atmos. Environ., 42, 2630-2642, doi:10.1016/j.atmosenv.2007.10.070, 2008.

Lyamani, H., Olmo, F. J., and Alados-Arboledas, L.: Physical and optical properties of aerosols over an urban location in Spain: Seasonal and diurnal variability, Atmos. Chem. Phys., 10, 239254, doi:10.5194/acp-10-239-2010, 2010.

Lyamani, H., Olmo, F. J., Foyo I., and Alados-Arboledas, L.: Black carbon aerosols over an urban area in south-eastern Spain: Changes detected after the 2008 economic crisis, Atmos. Environ., 45, 6423-6432, 2011.

Moosmüller, H., Chakrabarty, R. K., and Arnott, W. P.: Aerosol light absorption and its measurement: A review, J. Quant. Spectrosc. Ra., 110, 844-878, doi:10.1016/j.jqsrt.2009.02.035, 2009.

Müller, T., Henzing, J. S., de Leeuw, G., Wiedensohler, A., Alastuey, A., Angelov, H., Bizjak, M., Collaud-Coen, M., Engstrom, J. E., Gruening, C., Hillamo, R., Hoffer, A., Imre, K., Ivanow, P., Jennings, G., Sun, J. Y., Kalivitis, N., Karlsson, H., Komppula, M., Laj, P., Li, S.-M., Lunder, C., Marinoni, A., Martins dos Santos, S., Moerman, M., Nowak, A., Ogren, J. A., Petzold, A., Pichon, J. M., Rodriquez, S., Sharma, S., Sheridan, P. J., Teinila, K., Tuch, T., Viana, M., Virkkula, A., Weingartner, E., Wilhelm, R., and Wang, Y. Q.: Characterization and intercomparison of aerosol absorption photometers: result of two intercomparison workshops, Atmos. Meas. Tech., 4, 245-268, doi:10.5194/amt-4-245-2011, 2011.

Mukai, H. and Ambe, Y.: characterization of a humic acid-like Brown substance in airborne particulate matter and tentative identification of its origin, Atmos. Environ., 20, 813-819, 1986.

Nakayama, T., Kondo, Y., Moteki, N., Sahu, L. K., Kinase, T., Kita, K., and Matsumi, Y.: Size-dependent correction factors for absorption measurements using filter-based photometers: PSAP and COSMOS, J. Aerosol Sci., 41, 333-343, 2010.

Park, S. S., Hansen, A. D. A., and Cho, Y.: Measurement of real time black carbon for investigating spot loading effects of Aethalometer data, Atmos. Environ., 11, 1449-1455, 2010.

Petzold, A. and Schönlinner, M.: Multi-angle absorption photometry - a new method for the measurement of aerosol light absorption and atmospheric black carbon, J. Aerosol Sci., 35, 421-441, 2004.

Petzold, A., Kopp, C., and Niessner, R.: The dependence of the specific attenuation cross section on black carbon mass fraction and particle size, Atmos. Environ., 31, 661-672, 1997.
Petzold, A., Schloesser, H., Sheridan, P. J., Arnott, W., Ogren, J. A., and Virkkula, A.: Evaluation of multiangle absorption photometry for measuring aerosol light absorption, Aerosol Sci. Technol., 39, 40-51, 2005.

Ramanathan, V., Crutzen, P. J., Kiehl, J. T., and Rosenfeld, D.: Aerosols, Climate, and hydrological cycle, Science, 7, 21192124, 2001.

Rizzo, L. V., Correia, A. L., Artaxo, P., Procópio, A. S., and Andreae, M. O.: Spectral dependence of aerosol light absorption over the Amazon Basin, Atmos. Chem. Phys., 11, 8899-8912, doi:10.5194/acp-11-8899-2011, 2011.

Sandradewi, J., Prevot, A. S. H., Szidat, S., Perron, N., Lanz, V. A., Weingartner, E., and Baltensperger, U.: Using aerosol light absorption measurements for the quantitative determination of wood burning and traffic emission contributions to particulate matter, Environ. Sci. Technol., 42, 3316-3323, 2008 a.

Sandradewi, J., Prevot, A. S. H., Weingartner, E., Schmidhauser, R., Gysel, M., and Baltensperger, U.: A study of wood burning and traffic aerosols in an Alpine valley using a multi-wavelength aethalometer, Atmos. Environ., 42, 101-112, $2008 \mathrm{~b}$.

Schmid, O., Artaxo, P., Arnott, W. P., Chand, D., Gatti, L. V., Frank, G. P., Hoffer, A., Schnaiter, M., and Andreae, M. O.: Spectral light absorption by ambient aerosols influenced by biomass burning in the Amazon Basin. I: Comparison and field calibration of absorption measurement techniques, Atmos. Chem. Phys., 6, 3443-3462, doi:10.5194/acp-6-3443-2006, 2006.

Sheridan, P. J., Arnott, W. P., Ogren, J. A., Andrews, E., Atkinson, D. B., Covert, D. S., Moosmuller, H., Petzold, A., Schmid, B., Strawa, A. W., Varma, R., and Virkkula, A.: The Reno Aerosol Optics Study: An Evaluation of Aerosol Absorption Measurement Methods, Aerosol Sci. Technol., 39, 1-16, 2005.

Sun, H., Biedermann, L., and Bond, T. C.: Color of Brown carbon: A model for ultraviolet and visible light absorption by organic carbon aerosol, Geophys. Res. Lett., 34, L17813, doi:10.1029/2007GL029797, 2007.

Titos, G., Foyo-Moreno, I., Lyamani, H., Querol, X., Alastuey, A., and Alados-Arboledas, L.: Optical properties and chemical composition of aerosol particles at an urban location: An estimation of the aerosol mass scattering and absorption efficiencies, J. Geophys. Res., 117, D04206, doi:10.1029/2011JD016671, 2012.

Virkkula, A., Makel, T., Yli-Tuomi, T., Hirsikko, A., Koponen, I. K., Hameri, K., and Hillamo, R.: A simple procedure for correcting loading effects of aethalometer data, Japca J. Air Waste Manage., 57, 1214-1222, doi:10.3155/1047-3289.57.10.1214, 2007.

Weingartner, E., Saathoff, H., Schnaiter, M., Streit, N., Bitnar, B., and Baltensperger, U.: Absorption of light by soot particles: Determination of the absorption coefficient by means of aethalometers, J. Aerosol Sci., 34, 1445-1463, 2003. 